\title{
A large set of potential past, present and future hydro-meteorological time series for the UK
}

\author{
Benoit P. Guillod ${ }^{1, a, b}$, Richard G. Jones ${ }^{2,3}$, Simon J. Dadson ${ }^{3}$, Gemma Coxon ${ }^{4}$, Gianbattista Bussi $^{3}$, James Freer ${ }^{4}$, \\ Alison L. Kay ${ }^{5}$, Neil R. Massey ${ }^{1}$, Sarah N. Sparrow ${ }^{6}$, David C. H. Wallom ${ }^{6}$, Myles R. Allen ${ }^{1}$, and Jim W. Hall ${ }^{1}$ \\ ${ }^{1}$ Environmental Change Institute, University of Oxford, Oxford, UK \\ ${ }^{2}$ Met Office Hadley Centre, Exeter, UK \\ ${ }^{3}$ School of Geography and the Environment, University of Oxford, Oxford, UK \\ ${ }^{4}$ Geographical Sciences, University of Bristol, Bristol, UK \\ ${ }^{5}$ Centre for Ecology and Hydrology, Wallingford, UK \\ ${ }^{6}$ Oxford e-Research Centre, University of Oxford, Oxford, UK \\ ${ }^{a}$ currently at: Institute for Environmental Decisions, ETH Zurich, Zurich, Switzerland \\ ${ }^{b}$ currently at: Institute for Atmospheric and Climate Science, ETH Zurich, \\ Zurich, Switzerland
}

Correspondence: Benoit P. Guillod (benoit.guillod@env.ethz.ch)

Received: 25 April 2017 - Discussion started: 23 May 2017

Revised: 25 September 2017 - Accepted: 18 December 2017 - Published: 25 January 2018

\begin{abstract}
Hydro-meteorological extremes such as drought and heavy precipitation can have large impacts on society and the economy. With potentially increasing risks associated with such events due to climate change, properly assessing the associated impacts and uncertainties is critical for adequate adaptation. However, the application of riskbased approaches often requires large sets of extreme events, which are not commonly available. Here, we present such a large set of hydro-meteorological time series for recent past and future conditions for the United Kingdom based on weather@ home 2, a modelling framework consisting of a global climate model (GCM) driven by observed or projected sea surface temperature (SST) and sea ice which is downscaled to $25 \mathrm{~km}$ over the European domain by a regional climate model (RCM). Sets of 100 time series are generated for each of (i) a historical baseline (1900-2006), (ii) five nearfuture scenarios (2020-2049) and (iii) five far-future scenarios (2070-2099). The five scenarios in each future time slice all follow the Representative Concentration Pathway 8.5 (RCP8.5) and sample the range of sea surface temperature and sea ice changes from CMIP5 (Coupled Model Intercomparison Project Phase 5) models. Validation of the historical baseline highlights good performance for temperature and potential evaporation, but substantial seasonal biases in
\end{abstract}

mean precipitation, which are corrected using a linear approach. For extremes in low precipitation over a long accumulation period ( $>3$ months) and shorter-duration high precipitation (1-30 days), the time series generally represents past statistics well. Future projections show small precipitation increases in winter but large decreases in summer on average, leading to an overall drying, consistently with the most recent UK Climate Projections (UKCP09) but larger in magnitude than the latter. Both drought and high-precipitation events are projected to increase in frequency and intensity in most regions, highlighting the need for appropriate adaptation measures. Overall, the presented dataset is a useful tool for assessing the risk associated with drought and more generally with hydro-meteorological extremes in the UK.

\section{Introduction}

Extreme weather events such as droughts can have huge socio-economic consequences, so ensuring that society is well prepared to face such events will have multiple benefits. Anthropogenic climate change is expected to have an impact on extreme events: warm temperature extremes and heavy precipitation extremes have been shown to have in- 
creased due to human greenhouse gas emissions and these trends are projected to increase in the future (IPCC, 2013). These changes will increase risks in many regions and adequate adaptation will be critical to limit the associated damages.

Despite clear trends and predicted increases in these extremes, understanding of the implications for more complex hydro-meteorological extremes remains limited. This is the case of drought (e.g. Sheffield et al., 2012), for which the attribution of observed (projected) trends can only be done with low (medium) confidence (IPCC, 2013) due, among other factors, to observational uncertainty and confounding effects from decadal-scale variability combined with relatively small samples due to the comparatively long duration of droughts versus other extreme events. Nonetheless, some highlighted regions may be expected to experience more frequent or more intense droughts due to climate change (the Mediterranean region, central North America, Central America and Mexico, northeast Brazil and southern Africa; Seneviratne et al., 2012). Another complication is that drought can be caused by various factors including precipitation deficit, excessive potential evapotranspiration (due to enhanced radiation, wind speed or water pressure deficit) and pre-conditioning (pre-event land water storage including soil moisture, snow, lake and/or groundwater storage) (Seneviratne et al., 2012). Moreover, it can be defined in multiple ways as negative anomalies in precipitation ("meteorological drought"), soil moisture ("agricultural drought") or streamflow, lake or groundwater levels ("hydrological drought").

In the United Kingdom (UK), the issue of drought or, more generally, water scarcity, has been highlighted during the 2010-2012 drought. This drought drew attention to the potentially high economic losses that would result from a severe water restriction and prompted recognition that changes in climate and in water demand may increase the risk of such an event in the future, which highlighted the need to better assess the risk associated with drought in the UK. The MaRIUS project (Managing the Risks, Impacts and Uncertainties of drought and water Scarcity, http: //www.mariusdroughtproject.org) thus aims at better understanding the physical mechanisms and the inter-sectoral interactions leading to water scarcity, in order to support a riskbased approach for drought management.

Given the long duration, spatial variability and multivariate nature of droughts, large sets of potential drought events are required, in order to assess the impacts of these on various sectors and to apply a risk-based approach. Available data such as the most recent set of UK Climate Projections (UKCP09, Murphy et al., 2009) provide a large range of possible climate change signals, as well as long time series at any location derived from a weather generator. However, these long time series are not spatially consistent; i.e. one cannot examine interactions between spatially distributed locations, which is critical to the mentioned risk-based assessment, par- ticularly for drought. Other potential sources of data include climate model output from the Coupled Model Intercomparison Project Phase 5 (CMIP5, Taylor et al., 2012); however, while these provide a wide sampling of modelling uncertainty, they do so with a limited number of transient simulations for each model. The implied low number of simulated years impedes a proper estimation of the risk associated with rare events and, therefore, the application of risk-based management approaches, for which a large number of spatially consistent drought events are required.

Therefore, a new set of climate time series is created using weather@home 2 (Guillod et al., 2017a), an improved atmosphere-only global climate model (GCM) which is dynamically downscaled over a limited domain by a regional climate model (RCM) and run on volunteers' computers around the globe. Hydro-meteorological variables for hundreds of time series are generated over the UK for the recent past and for future time slices (Representative Concentration Pathway 8.5, RCP8.5, with climate response uncertainties), from which drought events can be identified. However, the use of the time series is not restricted to drought studies but can be applied to any type of extreme event. With about 3000 years of data for each 30-year period and scenario, the created dataset allows the examination of the very rare (and most severe) events with a high statistical confidence, albeit with limitations associated with the use of model-based data.

This paper presents the new hydro-meteorological climate time series. Section 2 describes the weather@home 2 model as well as observational datasets used for validation of the time series. The model simulations and the generation of the time series are detailed in Sect. 3. The time series covering the recent past are validated in Sect. 4, while the main features of the future projections are shown in Sect. 5.

\section{Model and data}

\subsection{Weather@home 2}

Weather@home (Massey et al., 2015) consists of an atmospheric global climate model, HadAM3P, and its regional counterpart, the regional climate model HadRM3P, which dynamically downscales the GCM to a higher resolution over a limited domain. As part of the climateprediction.net project (Allen, 1999),weather@ home takes advantage of computing time donated by volunteers around the world to run very large numbers of climate model simulations, of the order of tens of thousands.

The data analysed in this study is based on version 2 of weather@ home (hereafter, w@ h2, see Guillod et al., 2017a), which uses the more recent land surface scheme MOSES 2. The regional model covers the European CORDEX domain at a horizontal resolution of $0.22^{\circ}$ (about $25 \times 25 \mathrm{~km}$ ) on a rotated longitude-latitude grid (e.g. Kotlarski et al., 2014). 
The model, including its setup for this domain, is described and validated in detail by Guillod et al. (2017a).

\subsection{Observational data}

The gridded datasets listed in Table 1 are used for comparison and validation. For temperature, the E-OBS dataset (Haylock et al., 2008) is selected, as it is conveniently available on the same rotated longitude-latitude grid as HadRM3P. For precipitation, we use the CEH-GEAR dataset (Keller et al., 2015), which provides rainfall on a $1 \mathrm{~km}$ grid from 1890 to 2015. Observational estimates of potential evaporation are taken from the CHESS-PE dataset (Robinson et al., 2015), available from 1961 to 2012 and derived with two formulations, with and without correction for interception evaporation. For both CEH-GEAR and CHESS-PE, data are aggregated onto the $0.22^{\circ}$ model grid prior to all analyses.

\section{Methodology}

\subsection{Model simulations}

A total of 11 large ensembles ("batches") of w@h2 simulations are conducted, producing model output for three distinct time periods and a range of scenarios (see Table 2). The three time periods cover the past century ("historical baseline"; 1900-2006) and two 30-year future time slices (near and far future; 2020-2049 and 2070-2099, respectively) assuming the high greenhouse gas emission scenario RCP8.5 (Meinshausen et al., 2011). For each future time slice, uncertainty in transient climate response is taken into account by sampling a range of five sea surface temperature (SST) warming patterns derived from CMIP5 (Taylor et al., 2012), as detailed in Sect. 3.2, while for the historical baseline only one ensemble is generated, using the observed ocean state, leading to the total of 11 batches ( 1 batch for each time period and SST pattern).

All ensembles are generated using the same overarching design, described in Guillod et al. (2017a) for the historical baseline. Essentially, simulations are initialised on 1 December before each simulated year (e.g. 1 December from 2019 to 2048 for near future), using restart files from earlier 12month spin-up simulations, and are run for 13 months. The aim is to produce 100 simulations for each year (for each time slice and scenario), but, due to the nature of volunteer distributed computing, not all model simulations are completed at the same time. Therefore, in this case, 200-400 simulations per year are sent out and, whenever 100 simulations have been returned for each simulated year within a batch, this batch is closed and no additional simulation output is added to it. In cases when the minimum number of simulation per year did not reach 100 after some time, the batch was closed anyway, leading to a minimum number of simulations per year ranging from 85 to 100 depending on the scenario (Table 2).

Months 2-13 of the simulations being returned from each year are analysed, providing around 100 single-year simulations of data for each year (January to December), or a total of 10700 years of data for the historical baseline and 3000 years of data for each future time slice scenario.

For the historical baseline, the simulations are the same as those analysed by Guillod et al. (2017a). SSTs and sea ice are prescribed to observed values using version 2 of the HadISST dataset (Rayner et al., 2003; Titchner and Rayner, 2014). Similarly, other input variables such as greenhouse gas concentrations, volcanoes and solar activity, and $\mathrm{SO}_{2}$ concentrations are prescribed to historical values as described in Guillod et al. (2017a).

The future scenarios are 30-year time slices that correspond to years 1975-2004 of the historical baseline but with added climate change. Therefore, natural forcings (volcano and solar activity) are taken from 1975 to 2004, while greenhouse gases are taken from RCP8.5 for the simulated years (2020-2049 and 2070-2099). For sea surface temperature and sea ice, a similar approach is taken as in attribution studies (e.g. Schaller et al., 2016), but the future (rather than past) SST warming is added to (rather than subtracted from) observations. More specifically, the climate change signal derived from CMIP5 models (i.e. SST warming and corresponding changes in sea ice) is added to the 1975-2004 observed values used in the historical baseline. The details on the creation of future SST and sea ice are given in Sect. 3.2.

A number of daily and monthly variables are saved in the regional model (Table 3). Of particular relevance to hydrometeorology and extremes, the following variables are available at daily time steps from the regional model output: minimum and maximum temperature (tasmin and tasmax, respectively), precipitation, surface air humidity (mean dewpoint temperature), mean sea level pressure, and additional variables required to compute potential evaporation $\left(E_{\mathrm{pot}}\right)$ $(10 \mathrm{~m}$ wind speed, and incoming and net longwave and shortwave radiation fluxes at the land surface) as well as offlinecomputed $E_{\text {pot }}$ estimates (see Sect. 3.3 for details on the computation). In addition, 5-day averages of soil moisture on the four model levels as well as surface latent and sensible heat fluxes are available. All these variables, plus cloud cover and individual components of precipitation (convective versus large scale and snowfall versus rainfall) are available as monthly averages. Finally, weather@home is based on a calendar containing 360 days per year (i.e. 30 days per month), like many GCMs.

\subsection{Sea surface temperature projections}

To create the future SSTs and sea ice concentrations (SIC), two datasets are used: every available CMIP5 model simulation (Taylor et al., 2012), including all physics parameter and initial condition perturbations; and the HadISST2 
Table 1. Observational datasets. For the mean climate validation the common overlapping period 1961-2006 is used, while for precipitation extremes validation the overlap period between the historical baseline and CEH-GEAR (1900-2006) is used.

\begin{tabular}{llrrl}
\hline Variable & Dataset & Time period & Native resolution & Reference \\
\hline Temperature & E-OBS (version 12.0) & $1950-2014$ & $0.22^{\circ}$ & Haylock et al. (2008) \\
Precipitation & CEH-GEAR & $1961-2014$ & $1 \mathrm{~km}$ & Keller et al. (2015); Tanguy et al. (2015) \\
Potential evapotranspiration & CHESS-PE & $1961-2012$ & $1 \mathrm{~km}$ & Robinson et al. (2015) \\
\hline
\end{tabular}

Table 2. List of the climate time series for various scenarios. GM SST stands for global mean SST.

\begin{tabular}{|c|c|c|c|c|c|c|}
\hline Name & Short name & Years & $\begin{array}{l}\text { GM SST } \\
\text { percentile }\end{array}$ & $\begin{array}{l}\text { SST north } \\
\text { Atlantic index }\end{array}$ & No. of time series & Remark \\
\hline Historical baseline & bs & 1900-2006 & \multicolumn{2}{|c|}{ Observed (HadISST 2) } & 100 & $\begin{array}{l}\text { "Baseline" refers } \\
\text { to years 1975-2004 of } \\
\text { the historical baseline }\end{array}$ \\
\hline Near future & nf & 2020-2049 & 50 & 50 & 100 & \\
\hline Near-future p10n & nf-p10n & 2020-2049 & 10 & $\min$ & 91 & \\
\hline Near-future $\mathrm{p} 10 \mathrm{x}$ & nf-p10x & 2020-2049 & 10 & $\max$ & 91 & \\
\hline Near-future p90n & nf-p90n & 2020-2049 & 90 & $\min$ & 89 & \\
\hline Near-future $p 90 x$ & nf-p90x & 2020-2049 & 90 & $\max$ & 85 & \\
\hline Far future & ff & 2070-2099 & 50 & 50 & 100 & \\
\hline Far-future $\mathrm{p} 10 \mathrm{n}$ & ff-p10n & 2070-2099 & 10 & $\min$ & 89 & \\
\hline Far-future $\mathrm{p} 10 \mathrm{x}$ & ff-p10x & 2070-2099 & 10 & $\max$ & 86 & \\
\hline Far-future $p 90 n$ & ff-p90n & 2070-2099 & 90 & $\min$ & 90 & \\
\hline Far-future p90x & ff-p90x & 2070-2099 & 90 & $\max$ & 86 & \\
\hline
\end{tabular}

observed SST and SIC (Rayner et al., 2003; Titchner and Rayner, 2014). The CMIP5 model data are used to produce the large-scale warming patterns of SST for the two future time slices (2020-2049 and 2070-2099), whereas the HadISST data are used to provide the small-scale variability of the SST (whereby "small scale" refers here to anomalies from 30-year averages).

For the AMIP (climate model simulations with prescribed SSTs) component of the CMIP5 project, the projected change in SST and SIC are obtained from a single (per modelling group) coupled ocean-atmosphere model, and the models are integrated for a single decade from 2026 to 2035 . This approach has two disadvantages. Firstly, using a single model does not take into account the variation in the ensemble of CMIP5 models, both in the global mean SST (GMSST) and the pattern of warming produced. Secondly, the small-scale variability of the SST patterns do not match those in our observed dataset, which makes comparison between the historical scenario and the two future scenarios difficult. To get around these problems we construct a statistical model of SST warming patterns and impose the small-scale variability from the observed dataset, so as to match the historical scenario.

To construct the statistical model we use the SSTs for every model with data available for the RCP8.5 scenario. The below analysis is carried out for each month in the datasets, so as to reflect the greater warming in the DecemberFebruary season (DJF) in the CMIP5 ensemble. Firstly the SSTs are converted to anomalies by subtracting the 19862005 mean obtained from the corresponding historical run with the same model, run, initialisation and perturbation number. This gives a time series of SST anomalies for each CMIP5 ensemble member from 2006 to 2100 . Secondly, to remove the small-scale variability and generate the largescale warming patterns, a 30-year running-gradient filter is applied to every grid box in the SST anomalies.

The statistical model of SST warming patterns is constructed from these smoothed SST anomalies by first performing an empirical orthogonal function (EOF, Wilks, 2011) analysis on the smoothed SST anomalies for the year 2050. This produces a set of patterns (the EOFs) and principal components (PCs) which explain the variation in the smoothed SST anomalies across the CMIP5 ensemble members. The number of EOFs and PCs was truncated at six as, during the analysis, it was determined that the first six accounted for $98 \%$ of the variability. As we are interested in producing transient series of SSTs for two periods, the six EOFs were projected onto the smoothed SST anomalies for each year between 2020-2049 and 2070-2099 to produce time series of pseudo-PCs for each model and each year in the two scenarios. Next, a linear regression was performed on each set of pseudo-PCs for each year to derive a relationship 
Table 3. Output variables available in the dataset at various temporal frequencies.

\begin{tabular}{|c|c|c|c|}
\hline Temporal resolution & Variable name & Description & Unit \\
\hline \multirow{2}{*}{ Daily only } & tasmax & Maximum air temperature at $1.5 \mathrm{~m}$ above ground & $\mathrm{K}$ \\
\hline & tasmin & Minimum air temperature at $1.5 \mathrm{~m}$ above ground & $\mathrm{K}$ \\
\hline \multirow{12}{*}{ Daily and monthly } & $\mathrm{pr}$ & Mean precipitation flux & $\mathrm{mm} \mathrm{s}^{-1}$ \\
\hline & prbc & Bias-corrected pr (Sect. 4.1.2) & $\mathrm{mms}^{-1}$ \\
\hline & pepm & Penman-Monteith potential evaporation (Sect. 3.3) & $\mathrm{mm}_{\text {day }}{ }^{-1}$ \\
\hline & pepm_adjrs (future only) & $\begin{array}{l}\text { Future Penman-Monteith potential evaporation with stom- } \\
\text { atal resistance adjusted to atmospheric } \mathrm{CO}_{2} \text { concentration } \\
\text { (Sect. 3.3) }\end{array}$ & $\mathrm{mm} \mathrm{day}^{-1}$ \\
\hline & tdps & Mean dew-point temperature at $1.5 \mathrm{~m}$ above ground & $\mathrm{K}$ \\
\hline & wss & Mean wind speed at $10 \mathrm{~m}$ above ground & $\mathrm{ms}^{-1}$ \\
\hline & rsds & Mean incoming shortwave radiation at the surface & $\mathrm{Wm}^{-2}$ \\
\hline & rlds & Mean incoming longwave radiation at the surface & $\mathrm{Wm}^{-2}$ \\
\hline & rss & Mean net shortwave radiation at the surface & $\mathrm{Wm}^{-2}$ \\
\hline & rls & Mean net longwave radiation at the surface & $\mathrm{Wm}^{-2}$ \\
\hline & hfls & Mean latent heat flux at the surface & $\mathrm{Wm}^{-2}$ \\
\hline & psl & Mean sea level pressure & $\mathrm{Pa}$ \\
\hline Five-day averages and monthly & $\begin{array}{l}\text { hfss } \\
\text { moisture_content_of_soil_layer }\end{array}$ & $\begin{array}{l}\text { Mean sensible heat flux at the surface } \\
\text { Mean soil moisture content in each laver }\end{array}$ & $\begin{array}{l}\mathrm{Wm}^{-2} \\
\mathrm{~m}\end{array}$ \\
\hline \multirow{5}{*}{ Monthly only } & tas & Mean air temperature at $1.5 \mathrm{~m}$ above ground & $\mathrm{K}$ \\
\hline & prsn & Total snowfall flux & $\mathrm{mm} \mathrm{s}^{-1}$ \\
\hline & prrc & Convective rainfall flux & $\mathrm{mm} \mathrm{s}^{-1}$ \\
\hline & prsnc & Convective snowfall flux & $\mathrm{mm} \mathrm{s}^{-1}$ \\
\hline & clt & Fractional cloud cover & - \\
\hline
\end{tabular}

Table 4. Monthly surface resistance values $\left(r_{\mathrm{s}}\right.$, in $\left.\mathrm{sm}^{-1}\right)$ used in the computation of $E_{\text {pot }}$. The baseline values are shown under pepm and are kept constant in future time slices for variable pepm. pepm_adjrs denotes the future values accounting the changes in $\mathrm{CO}_{2}$ concentration (see Sect. 3.3 for details).

\begin{tabular}{lrrr}
\hline Months & pepm & $\begin{array}{r}\text { pepm_adjrs } \\
\text { (near future) }\end{array}$ & $\begin{array}{r}\text { pepm_adjrs } \\
\text { (far future) }\end{array}$ \\
\hline January & 88.7 & 94.5 & 115.9 \\
February & 88.7 & 94.5 & 115.9 \\
March & 69.5 & 75.8 & 101.6 \\
April & 56.8 & 62.7 & 88.5 \\
May & 44.5 & 49.5 & 72.2 \\
June & 64.3 & 71.2 & 102.1 \\
July & 64.3 & 71.2 & 102.1 \\
August & 73.7 & 81.5 & 115.8 \\
September & 75.4 & 82.8 & 114.2 \\
October & 78.0 & 84.8 & 112.1 \\
November & 87.1 & 93.7 & 118.8 \\
December & 88.7 & 94.5 & 115.9 \\
\hline
\end{tabular}

between the pseudo-PCs in that year and the PCs in 2050 . These PC relationships are used in the reconstruction of the SSTs later.

The core of the statistical model is a multi-variate distribution (MVD) of the truncated PCs in the year 2050, modelled by a Gaussian copula (Nelsen, 2007) with skew-normal marginals (Azzalini, 2005) using the "copula" and "sn" pack- ages in the $\mathrm{R}$ statistical analysis software ( $\mathrm{R}$ Core Team, 2016). A MVD is used as, although the EOFs are orthogonal to each other, the signs of the PCs within an ensemble member are not independent. Once the copula has been constructed it is sampled 10000 times, which produces a set of six PCs for each sample. The SST warming pattern is then reconstructed from these PCs and the EOFs for the year 2050, and the GMSST of the warming pattern is calculated and recorded with the PCs. This allows the construction of a probabilistic distribution of the GMSST warming in the CMIP5 ensemble which also contains the information (PCs) of how to construct the GMSST. Note that, for a given percentile, there will be 100 different sets of PCs. This allows the construction of up to 100 different warming patterns for each GMSST value, where the contributions to the mean warming occur in different physical locations. For this experiment we choose the 10th, 50th and 90th percentile values of GMSST so as to incorporate CMIP5 models with both low and high sensitivity in their GMSST response to elevated greenhouse gas concentrations.

Weather in the UK is potentially sensitive to the North Atlantic (NA) SSTs and in particular to gradients thereof (e.g. Rodwell et al., 1999; Rodwell and Folland, 2002). To account for this we use a NA SST gradient index to select the two most different warming patterns, in relation to this metric, from the 100 potential warming patterns for each of the 10th and 90th percentiles. This gradient is defined as the difference between the area-weighted means of two areas in 
the North Atlantic, following Schaller et al. (2016): A southern area bounded by the longitude-latitude coordinates 30 $50^{\circ} \mathrm{N}, 40-0^{\circ} \mathrm{W}$ and a northern area bounded by $50-70^{\circ} \mathrm{N}$, $40-0^{\circ} \mathrm{W}$.

From the sampling of the output of the copula we form five warming patterns for the year 2050, by combining the PCs with the EOFs: p10n corresponds to the pattern with a GMSST warming at the 10th percentile and the minimum NA SST gradient, $\mathrm{p} 10 \mathrm{x}$ the 10th percentile GMSST and the maximum NA SST gradient, p90n the 90th percentile and the minimum NA SST gradient, and p90x the 90th percentile and maximum NA SST gradient, and MMM a median scenario with the median GMSST and middle NA SST gradient. Each of these patterns has an associated set of PCs for the year 2050. To generate a time series of SST anomalies the linear relationship between the original PCs in the year 2050 and the pseudo-PCs is used to construct time series of PCs for each of the 5 warming patterns above. These PCs (derived from the linear relationship) are then combined with the EOFs for the year 2050 to generate a time series of SST anomalies between the years 2020-2049 and 2070-2099 for each of the 5 warming patterns.

To generate absolute climatological SST values, the time series of SST anomalies are added to the 1986-2005 mean of the HadISST2 dataset (since the above procedure was applied to anomalies from those same years). Since the future time slices are to be compared to the reference time period 1975-2004 (baseline), the small-scale variability from these years is then also added onto the sum of the SST anomalies and HadISST mean. This small-scale variability is also derived from the HadISST2 data by applying the 30year smoother and then subtracting the smoothed data from the original HadISST2 data. This calculates the residuals of the smoother for 1975-2004 when compared to the original data source and removes the large-scale variability from HadISST, which was already added by the warming patterns.

To construct the sea ice we use the 10 best CMIP5 models at representing historical sea ice between 1979 and 2005, as ranked by Shu et al. (2015). For each future period (20202049 and 2070-2099), for every grid box we pool the SST anomalies for the RCP8.5 scenario and the corresponding SIC anomalies. We then derive a linear relationship, for each grid box, between the SST anomaly and the SIC anomaly by using a linear regression. Time series of SIC absolute values are then constructed for each grid box by calculating the SIC anomaly from the time series of SST anomalies computed above and the linear relationship between the SST anomaly and SIC anomaly. The 1986 to 2005 mean of the HadISST2 SIC is then added to the time series of SIC anomalies and then some post-processing is performed. Firstly, ice holes, which occur where a grid box with no ice is surrounded by eight grid boxes with ice, are filled with the mean value of the eight surrounding grid boxes. Secondly, isolated ice, where a grid box with ice is surrounded by grid boxes with no ice, is removed by setting the SIC in the grid box to 0 . Thirdly, a longitudinal smoother is applied to the resulting data field.

As a result of this procedure, five SST time series are obtained for each future time slice (near and far future), which have the same small-scale variability as the 19752004 HadISST SSTs and sample the inter-model variability in SST warming from CMIP5 both in terms of the GMSST and NA SST gradient. These five patterns are hereafter referred to as scenarios and are summarised in Table 2. Supplement Figs. S1 and S2 display the resulting warming imposed on observed SSTs for near and far-future scenarios, by season and scenario.

\subsection{Potential evaporation estimates}

Potential evaporation $\left(E_{\mathrm{pot}}\right)$ is defined as the amount of water that would evaporate from the land surface (soil, vegetation) into the atmosphere if soil moisture supply was not limiting. Although a form of $E_{\mathrm{pot}}$ is computed in the code of the land surface model MOSES 2, it cannot be directly saved as an output and must therefore be computed offline from the meteorological model output. Since $E_{\text {pot }}$ is an important variable that is used as an input to some impact models (e.g. hydrological models), this computation is done and the estimated $E_{\text {pot }}$ time series are included in the dataset along with the other variables. To do so, we estimate daily $E_{\text {pot }}$ (in mm day ${ }^{-1}$ ) from the atmospheric model output based on the Penman-Monteith equation (Monteith, 1965) as follows (modified from Rudd and Kay, 2016):

$E_{\text {pot }}=\frac{1}{\lambda} \frac{\Delta R_{\mathrm{n}}+\rho_{\mathrm{a}} c_{\mathrm{a}}\left(e_{\mathrm{s}}-e_{d}\right) / r_{\mathrm{a}}}{\Delta+\gamma\left(1+r_{\mathrm{s}} / r_{\mathrm{a}}\right)}$,

where the following variables depend on the atmospheric variables: $\Delta$ is the rate of change of saturated vapour pressure with temperature $\left(\mathrm{kPa}^{\circ} \mathrm{C}^{-1}\right), R_{\mathrm{n}}$ is net radiation at the surface $\left(\mathrm{W} \mathrm{m}^{-2}\right), e_{\mathrm{s}}$ is the saturation vapour pressure at nearsurface air temperature $(\mathrm{kPa}), e_{d}$ is the near-surface vapour pressure $(\mathrm{kPa}), r_{\mathrm{a}}$ is the aerodynamic resistance to vapour transfer in the atmosphere $\left(\mathrm{s} \mathrm{m}^{-1}\right)$ and $r_{\mathrm{s}}$ is the bulk surface (canopy or bare soil) resistance $\left(\mathrm{s} \mathrm{m}^{-1}\right)$. The following are constants in Eq. (1): $\lambda$ is the latent heat of evaporation $\left(2.45 \times 10^{6} \mathrm{~J} \mathrm{~kg}^{-1}\right), \rho_{\mathrm{a}}$ is the near-surface air density $\left(1 \mathrm{~kg} \mathrm{~m}^{3}\right), c_{\mathrm{a}}$ is the specific heat of air $\left(1013 \mathrm{~J} \mathrm{~kg}^{-1}{ }^{\circ} \mathrm{C}^{-1}\right)$ and $\gamma$ is the psychrometric constant $\left(0.066 \mathrm{kPa}^{\circ} \mathrm{C}^{-1}\right)$.

The saturation vapour pressure $e_{\mathrm{s}}$ can generally be computed from temperature $T$ (in ${ }^{\circ} \mathrm{C}$ ) as

$e_{\mathrm{S}}(T)=0.611 \exp \left(\frac{17.27 T}{T+237.3}\right)$.

Therefore, we can derive

$\Delta=\frac{\mathrm{d} e_{s}}{\mathrm{~d} T}=17.27 \cdot 237.3 \frac{e_{\mathrm{S}}(T)}{(T+237.3)^{2}}$,

where $T$ is approximated by the average of daily minimum and daily maximum temperature $(T=(\operatorname{tasmin}+\operatorname{tasmax}) / 2)$. 
For the computation of $e_{\mathrm{S}}$ itself from daily data, however, we use a more accurate approach consisting of averaging $e_{\mathrm{s}}$ values estimated from daily minimum and maximum temperature (tasmin and tasmax), i.e.

$e_{\mathrm{S}}=\frac{e_{\mathrm{S}}(\operatorname{tasmin})+e_{\mathrm{S}}(\operatorname{tasmax})}{2}$.

The near-surface vapour pressure can be directly estimated from daily averaged dew-point temperature (tdps, in ${ }^{\circ} \mathrm{C}$ ) based on Eq. (2),

$e_{d}=0.611 \exp \left(\frac{17.27 \mathrm{tdps}}{\mathrm{tdps}+237.3}\right)$,

and the aerodynamic resistance is computed from the daily mean $10 \mathrm{~m}$ wind speed (wss, in $\mathrm{m} \mathrm{s}^{-1}$ ) using

$r_{\mathrm{a}}=\frac{243.489}{\mathrm{wss}}$,

hence including a logarithmic correction for wind height.

Finally, surface resistance $r_{\mathrm{s}}$ is computed as in Rudd and Kay (2016), consistently with MORECS $E_{\text {pot }}$ estimates (Hough and Jones, 1997) and leading to the monthly surface resistance values shown in Table $4 . E_{\text {pot }}$ is not only affected by meteorological conditions, but also by vegetation. In particular, for future projections an important driver for vegetation is the ambient $\mathrm{CO}_{2}$ concentration: plant stomata may need to open less widely with higher $\mathrm{CO}_{2}$ concentrations, thereby conserving water (e.g. Keenan et al., 2013). Not accounting for this effect in offline $E_{\text {pot }}$ estimations has been shown to lead to an overestimation of continental drying (Milly and Dunne, 2016), which is particularly relevant for drought analyses. Therefore, along with $E_{\text {pot }}$ estimates for future time slices using the same $r_{\mathrm{s}}$ value as in the baseline (variable pepm), an additional variable (pepm_adjrs) is introduced, which accounts for the impact of $\mathrm{CO}_{2}$ on stomatal resistance and, therefore, on $E_{\text {pot }}$. To do so, we follow Rudd and Kay (2016) and use the estimate of change in crop and grass conductance per $1 \mathrm{ppm} \mathrm{CO}_{2}$ concentration increase of Kruijt et al. (2008) $\left(-9.3 \times 10^{-2} \%\right)$ and apply these to change in the 30 -year averaged $\mathrm{CO}_{2}$ concentration between each future time period $(469.5 \mathrm{ppm}$ in the near future and $798.6 \mathrm{ppm}$ in the far future) and 1975-2004 values $(352.7 \mathrm{ppm})$. The resulting monthly $r_{\mathrm{s}}$ values are displayed in Table 4 for pepm and pepm_adjrs for near and far future.

Both variables (pepm and pepm_adjrs) are computed for each day using the $r_{\mathrm{s}}$ value of the corresponding month, and monthly values are subsequently computed by averaging the daily values.

\subsection{Generation of continuous time series from single years}

Unlike other extreme events such as heat waves, heavy precipitation or cold spells, droughts often extend over months to years. While for short events (i.e. from a day to, say, 1 month) the direct use of single-year simulations can be suitable, longer, continuous time series are required to study droughts. However, a limitation of weather@home is that it can generate simulations of only relatively short durations owing to the relatively slow computation on volunteers' personal computers. Here, we develop a methodology to derive plausible long continuous time series from a large ensemble of single-year simulations, whereby simulations in a given year are "stitched" to those of the next year using an appropriate criterion.

The criterion based on which simulations are stitched ideally ensures that the weather history of a simulation is consistent with the conditions found at the beginning of the next year's simulation to which it is stitched to. Given the slow nature of the temporal evolution of droughts, emphasis is put on obtaining continuous time series not necessarily from one day to the next, but rather on a temporal scale of the order of a week. Additionally, given the use of a large ensemble of simulations to construct multiple time series, the objective is not to derive time series that are really continuous (a task that may be considered impossible given the chaotic nature of the atmosphere), but rather to derive a set of time series that can be considered as continuous in the sense that their statistics can hardly be distinguished from those of continuous simulations. Therefore, we focus on those components of the climate system that exhibit significant temporal memory (or autocorrelation) and that may impact the atmosphere. The ocean (i.e. sea surface temperature and sea ice) is a major component with these characteristics; however, being prescribed to observations in our simulations, it is continuous by definition and hence it does not need additional consideration for stitching purposes. Another such component is the land surface, in particular soil moisture. Soil moisture exhibits a few relevant characteristics: first, it exhibits memory of typically a few weeks to months (e.g. Koster and Suarez, 2001) and, therefore, one may want to ensure that this memory is not lost in the stitching process this may be particularly critical in the case of droughts. Second, the temporal evolution of soil moisture is mainly driven by precipitation minus evapotranspiration $(P-E)$, i.e. by the weather in previous weeks to months. In other words, soil moisture can be seen as an approximate integrator of $P-E$ over time. Ensuring that soil moisture is continuous therefore also likely constrains the history of the weather, which in turn increases the temporal consistency in atmospheric conditions in the stitched time series (for example, simulations with wet soils at the end of a year are likely to have exhibited wet conditions in December, while simulations with dry soils at the end of the year likely display less rainfall and higher temperature in December). Finally, soil moisture has been shown to be involved in key feedbacks relevant to droughts and heat waves (Seneviratne et al., 2010), such as soil moisture-temperature (Hirschi et al., 2011; Miralles et al., 2014) and soil moisture-precipitation (Roundy et al., 
2013; Guillod et al., 2015) feedbacks. Therefore, ensuring continuous soil moisture avoids biases in the statistics of the weather in the following few weeks. Note that this last characteristic is most relevant in transitional regions between wet and dry climate and is probably not critical in the UK in the winter season, when our simulations are stitched. Other variables that could have been considered include snow; however, given that snow is not very frequent at the end of December over the UK, it may be difficult to distinguish between the large number of simulations which do not exhibit any snow at all.

Based on these considerations, we use soil moisture as a basis for stitching. Figure 1 displays an example of time series that are obtained with our simulation setup for two consecutive years, with the first month of the simulations (grey lines, implicitly part of a 13-month spin-up) leading to 12 month simulations (coloured). Stitching the 1990 simulations to the 1991 simulations is based on identifying the best match between the 1990 end-of-simulation values (last value for each simulation) and the value at the same time step in the 1991 simulations, i.e. the last value in the spin-up (in grey) leading to the 1991 simulations. Five-day averages (i.e. pentads) of soil moisture in the upper $1 \mathrm{~m}$ of the soil (three out of four model levels in this case) over the British Isles are used for this purpose.

While Fig. 1 is useful to understand the principle of the stitching methodology, the problem is more complex for gridded data as there are multiple locations (or grid cells) and, thus, multiple time series to consider for each set of simulations. An appropriate simplification of this problem is to ensure continuity of the main spatial patterns of soil moisture. To do this, we concentrate on the main modes of variability by computing the EOFs for the last pentad of December at the end of our simulations (Fig. 2). The leading EOF pattern is homogeneous in sign and thus characterises the overall soil moisture conditions within the analysed domain, while the second EOF characterises a southeast-northwest contrast. Together, these two leading EOFs explain $60 \%$ of the total variance, while further EOFs account for a much lower fraction of the variability ( $6 \%$ and lower). Hence, we retain these two EOFs and use the reduced two-dimensional space of the principal components corresponding to these EOFs (hereafter, PC1-2 space) to compare soil moisture fields and find similar conditions, defined by the lowest possible distance in this two-dimensional space.

The procedure used for stitching is as follows.

1. Wait until a minimum of $n$ simulations is available for each year, which will allow the creation of $n$ time series (e.g. $n=100$ for historical baseline).

2. Compute the PCs of soil moisture at the last pentad of December in months 1 ("start of run") and 13 ("end of run") of each simulation, i.e. obtaining the starting and ending soil moisture conditions.
3. Starting with the year $Y$ with the lowest number of simulations available $(=n)$, all simulations are stitched forward as follows: the distance in the soil moisture PC1-2 space between each end-of-run value from simulations on year $Y$ and each start-of-run value from simulations on year $Y+1$ is computed. The Hungarian algorithm ( $\mathrm{R}$ function "solve_LSAP" in package "clue", Kuhn, 1955, 1956; Papadimitriou and Steiglitz, 1982; Hornik, 2005, 2016) is then applied to find the combination that minimises the sum of the squared distances.

4. The year $Y+1$ simulations that have been selected are used and the previous step is repeated until the last year of the time series is reached.

5. The same procedure is applied backward, i.e. matching start-of-run values on year $Y$ to end-of-run values on year $Y-1$. This is done repeatedly until the first year of the time series is reached.

The output of this procedure is a table which lists, for each time series, the simulation identifier for each year. The performance of the stitching methodology is evaluated from the historical baseline (1900-2006) by considering the soil moisture error obtained through stitching, using the comparison of stitched and continuous simulations.

Figure 3a shows the distribution of simulations in the PC1-2 space, for the last pentad in December. As detailed above, to create continuous time series, soil moisture at the end of the simulations on year $Y$ (month 13 of the simulation; last December pentad) is compared to soil moisture at the same time step in month 1 of simulations leading to year $Y+1$. The distribution of the obtained distances in the PC12 space at the time of stitching is shown in black on Fig. $3 b$. To evaluate this in the context of a continuous simulation, we analyse changes between consecutive soil moisture pentads in continuous simulation (continuous lines on Fig. 3bd), taken from the last pentad in December to any of the first three pentads in January (i.e. transition at the beginning of our simulations). We find that the difference at the time of stitching (dashed black line) is substantially smaller than typical changes with a lag of one pentad in continuous simulations (continuous green line), both in terms of distance in PC1-2 space (Fig. 3b) and changes in these PCs considered individually (Fig. 3c, d); i.e. the soil moisture error is smaller than a temporal lag of one pentad. Furthermore, changes between the last December and first January pentads (i.e. with a lag of one) are only slightly larger in the stitched ensemble (dashed lines) than in continuous simulations (continuous lines). For a lag of three pentads (purple), the changes in soil moisture PCs are very similar in stitched and continuous simulations. In these panels, these changes can also be compared to what would happen in a randomly stitched ensemble (dotted lines). The changes in such an ensemble are, as expected, independent of the lag (since no temporal correlation is retained) and are substantially larger than 

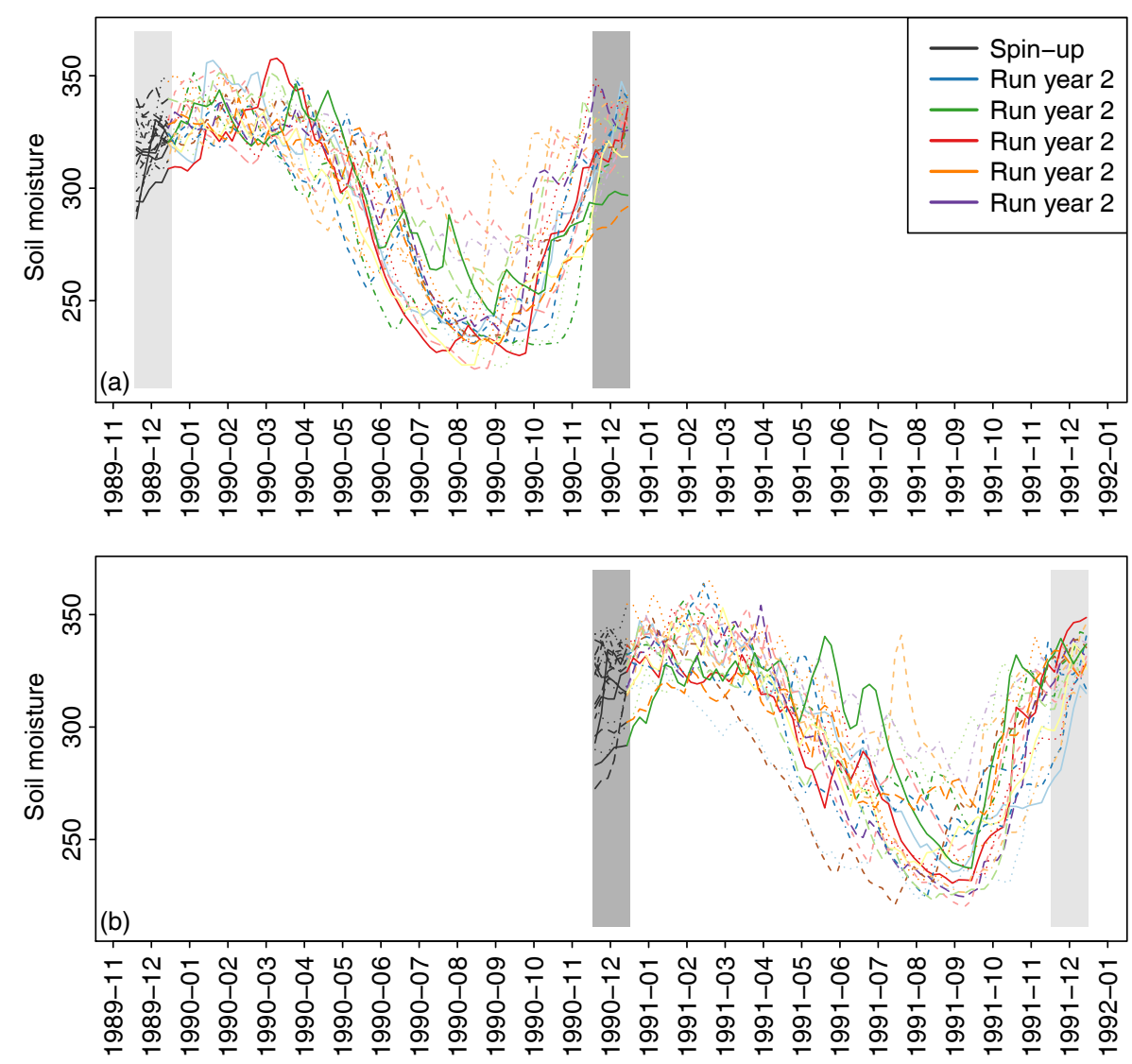

Figure 1. Illustration of the simulation design and stitching, using soil moisture model data averaged over the Thames catchment. Each panel shows, for a given year (a: 1990; b: 1991), 5-day averages of soil moisture in the upper $1 \mathrm{~m}$ of the soil for 20 model simulations. The first month of the simulations (December of the previous year, part of the spin-up) is indicated by grey lines, followed by the 12 months (January to December) in colours. End-of-year values of 1990 simulations and the same time steps in the spin-up leading to 1991 values, highlighted by dark grey boxes, have to be compared to find the combination allowing the best match between simulations. Light grey boxes indicate the same time steps that will be used to stitch to 1989 (a) and 1992 (b).

those found in both the soil-moisture-stitched and continuous ensembles (dotted lines, lying on top of each other for all lags). These results show that the presented methodology allows successfully stitching single-year simulations to each other, thereby ensuring consistency in weather statistics on timescales of weeks.

\section{Validation of the historical baseline}

The global and regional models in weather@home 2 have been validated thoroughly in Guillod et al. (2017a) with respect to the simulated mean climate, trends and extremes, including the British Isles domain averages. Here, we further validate the 100 baseline time series on a more local scale over the UK. Section 4.1 investigates the biases in mean climate and describes the bias correction taken to alleviate major biases, while Sect. 4.2 focuses on hydro-meteorological extremes, i.e. low and high-precipitation events. In addition to maps, some of the analyses are conducted for 19 river basin regions within Great Britain used in the UKCP09 climate projections (Murphy et al., 2009) and shown in Fig. S3.

\subsection{Mean climate and bias correction}

\subsubsection{Mean biases}

Figure $4 a-d$ shows the seasonal biases in surface air temperature with respect to the E-OBS dataset (Haylock et al., 2008). Biases are remarkably small for raw climate model output (within $1^{\circ} \mathrm{C}$ and often below $0.5^{\circ}$ ), with two main exceptions: a cold bias present in all seasons in the northwest (Argyll region) and a warm bias in summer (June to August, JJA) in the south and southeast.

Biases in precipitation with respect to the CEH-GEAR dataset (Fig. 4e-l), on the other hand, are more significant. In particular, precipitation is strongly underestimated in summer (20-50\% or up to $\left.1 \mathrm{~mm} \mathrm{day}^{-1}\right)$ and, to a lower extent, in autumn. Conversely, winter precipitation tends to be overestimated in the southeast. Possible mechanisms for these biases 
(a) EOF $1(44 \%)$

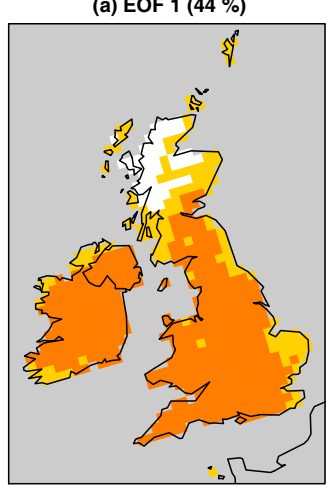

(c) EOF 3 (6\%)

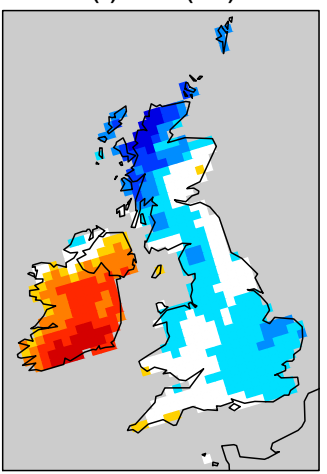

(b) EOF 2 (16\%)

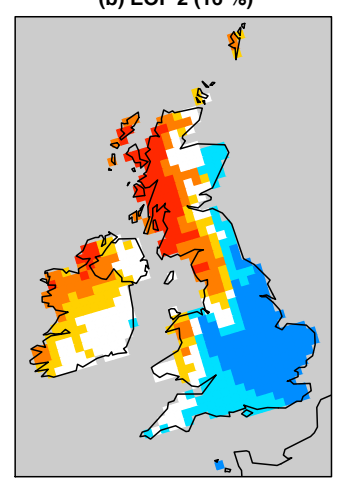

(d) EOF 4 (5\%)

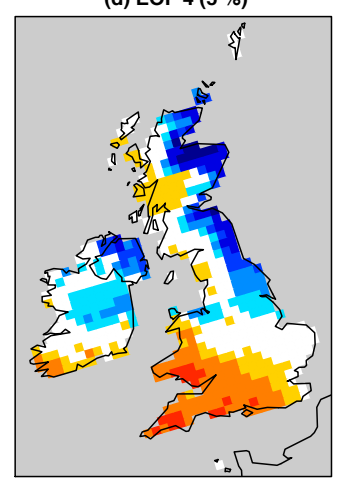

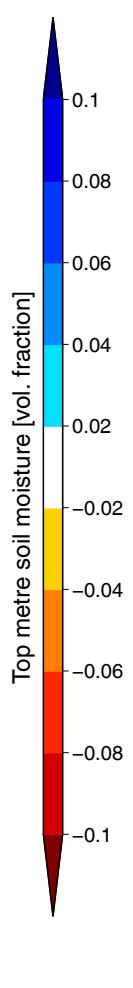

Figure 2. Leading EOFs of upper 1m soil moisture over the British Isles in the last pentad in December. The fraction of explained variance is indicated on each panel.

are discussed in Guillod et al. (2017a). These biases have implications, particularly for the investigation of droughts and future drought risk, and the application of a bias-correction technique is therefore necessary. The next Sect. 4.1.2 describes the approach chosen to correct precipitation data.

Another important variable for hydro-meteorological extremes is $E_{\text {pot }}$, whose biases are shown in Fig. $4 \mathrm{~m}-\mathrm{p}$ with respect to CHESS-PE (without interception correction) and highlight an overestimation in summer (in the order of $20 \%$ ) relative to this dataset. A possible reason for this overestimation is the warm temperature bias in this season, although possible biases in the radiative (net radiation) or aerodynamic (wind) components could also play a role. This bias should be kept in mind by users of the data, in particular when analysing droughts since these may thereby be overestimated. However, we note that large uncertainties are associated with the estimation of $E_{\text {pot }}$ in both models and observations, stemming among others from the formula and parameters used and, for observations, from the input data sources (Milly and Dunne, 2017).

\subsubsection{Bias correction}

With the biases in temperature being relatively small, they are not explicitly corrected. Although correcting the biases in $E_{\text {pot }}$ might seem appealing owing to their significant amplitude, such a procedure is not attractive since it comes with strong assumptions that might not hold. First, the origin of $E_{\text {pot }}$ biases may be multiple, from temperature biases to bias in the radiation (e.g. overestimated net radiation owing to underestimated cloud cover) and aerodynamic (wind) components of the $E_{\text {pot }}$ computation. Hence, to properly biascorrect $E_{\text {pot }}$, variables used to compute it should be corrected individually before computing $E_{\text {pot }}$. However, the lack of long-term gridded observations at a suitable resolution for some of these variables hampers such a procedure. Second, $E_{\text {pot }}$ is not observed directly but estimated from meteorological variables, leading to large discrepancies between observed estimates owing to various assumptions (formulation, parameters) and data used to compute them. This implies that a bias-corrected $E_{\text {pot }}$ would be highly dependent on the chosen source of observed $E_{\text {pot }}$. Third, the assumption that the same bias correction can be applied to future scenarios would be even more questionable for $E_{\text {pot }}$ than for precipitation because of the interdependence of the variables used to compute it. Based on these considerations, $E_{\text {pot }}$ is not bias corrected in our dataset. However, users are recommended to investigate whether these biases have an impact on their results and to take these into account, especially when investigating summer drought. This recommendation also applies to users that compute $E_{\text {pot }}$ themselves using an alternative formulation.

By contrast, the substantial precipitation biases may be particularly problematic for drought analysis and correcting for these is therefore necessary. To do so, a simple linear approach was chosen, using monthly bias-correction factors (e.g. Lafon et al., 2013). The choice of bias-correction algorithm depends on the nature of the biases present and the uncertainty with which properties of the observed and modelled precipitation distributions can be estimated (e.g. Teutschbein and Seibert, 2012; Lafon et al., 2013). For example, if biases are present in higher-order moments of the simulated precipitation distribution, then more sophisticated bias-correction techniques are warranted than if only the mean is biased. Nonetheless, the higher-order moments of the precipitation record can only be corrected if they can be estimated with confidence, which is not always possible for short-duration datasets. There is therefore a trade-off between reducing biases and introducing additional (often unconstrained) uncertainty. As recommended by Lafon et al. (2013), we use the simplest possible method which is able to correct significant biases in the data. In the present analysis we use a linear bias correction, which we calculate offers adequate correction of seasonal biases in the mean and which does not adversely affect higher-order moments of the rainfall distribution. It is also noted that for drought studies using climate model outputs the distribution of dry days (i.e. days with precipitation $<1 \mathrm{~mm}$ ) can be important to preserve. In the present case we find that this distribution is maintained without further specific corrections (Fig. S4). These were defined based 
(a) Distribution of simulations in PC1-2 space

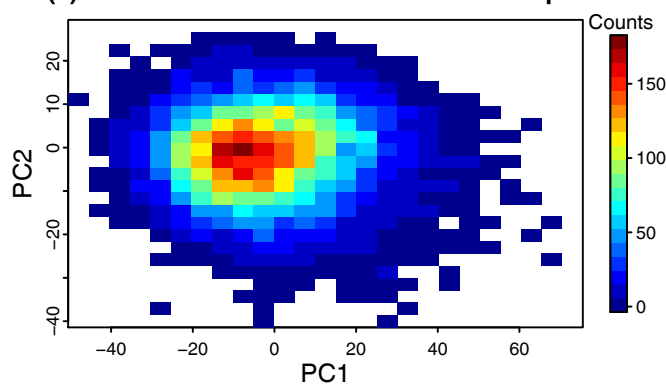

(c) Ecdf of change in PC1

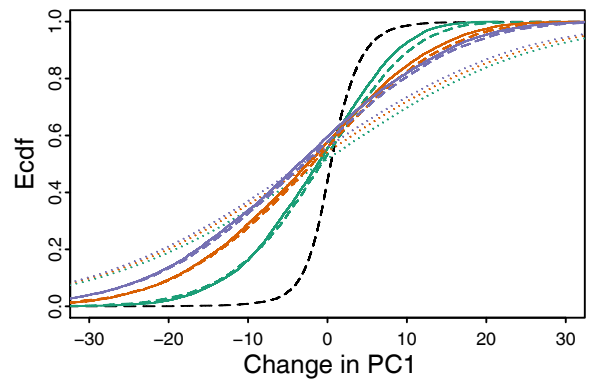

(b) Ecdf of change: distance in PC1-2 space

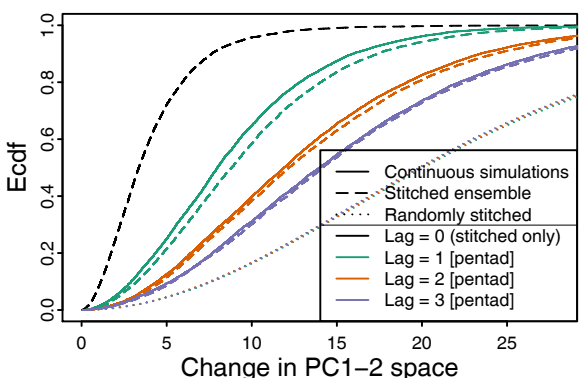

(d) Ecdf of change in PC2

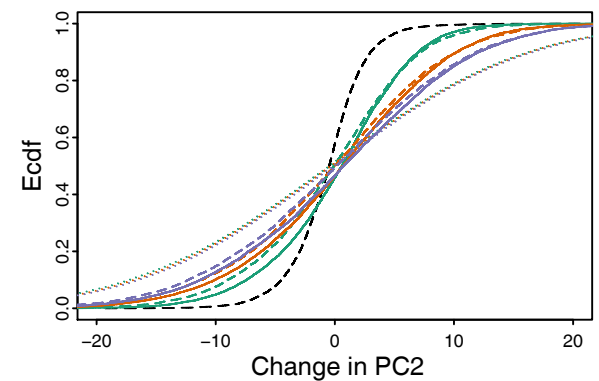

Figure 3. Temporal continuity of soil moisture in the stitched ensemble compared to continuous simulations in the historical baseline (1900-2006). (a) Bivariate distribution of soil moisture PCs 1 and 2 at the last December pentad. (b-d) Empirical cumulative distribution function (ecdf) of the changes in the PC1-2 space between the last pentad in December and the three subsequent pentads (colours) in continuous simulations (continuous lines), the stitched ensemble (thick lines) and a randomly stitched ensemble (points). The dashed black line shows the ecdf of the same distance at the time of stitching, i.e. between the same pentad in stitched simulations. (b) Absolute distance in the PC1-2 space, (c) change in PC1 and (d) change in PC2.

on the overlapping time period between all observational datasets (CEH-GEAR, CHESS-PE, E-OBS) and our baseline, i.e. years 1961-2006. The mean precipitation for each calendar month was computed from the 100 baseline time series, and their ratio to the corresponding values in $\mathrm{CEH}$ GEAR were computed (Fig. S5). However, in order to avoid sudden discontinuities between grid cells, a spatial smoothing was applied to the ratio using a 3-by-3 grid cells moving box and taking weights of $1 / 2$ for the centre box and $1 / 16$ for the surrounding eight boxes, leading to the precipitation bias-correction factors shown in Fig. 5. Note that only the Great Britain coverage of CEH-GEAR data is used for bias correction, since CEH-GEAR data over Northern Ireland are available as a separate product and have not been processed.

Subsequently, daily and monthly precipitation values were multiplied by the factor for the corresponding month. The bias-corrected precipitation is also made available as part of the dataset as an additional variable (prbc, see Table 3). Unless explicitly mentioned, analyses in the rest of this study are based on bias-corrected precipitation data.

\subsubsection{Inter-member variability}

While the previous two subsections only consider the model climatology averaged from all 100 time series, part of the dif- ference with observation may arise from natural variability, as expressed from the climatology of the individual time series. Indeed, although we often consider the observed climatology as the true climatology (albeit with some measuring errors), it is in fact one possible climatology among many and is determined by the one trajectory through the "weather phase space" that occurred by chance. This is due to the highly non-linear, chaotic behaviour of the atmosphere (e.g. Lorenz, 1965).

To assess the variability in climatologies in the 100 time series, Figs. S6-S9 display the full range, interquartile range and median of climatologies (out of the 100 modelled climatologies) as well as observations for the 19 river basin regions. For temperature (Fig. S6), all climatologies are relatively similar, but a larger spread is found for precipitation (Figs. S7 and S8 for raw and bias-corrected values, respectively). Nonetheless, the observed climatology generally lies outside of all 100 climatologies for the main biases. It should be noted that some biases persist after bias correction (e.g. in the Western Highland and Tay regions on Fig. S8) due to the spatial smoothing applied to the bias-correction factors. For $E_{\text {pot }}$ (Fig. S9), both variants from the CHESS-PE dataset are shown (with and without interception correction) and the main features are captured relatively well, apart from 

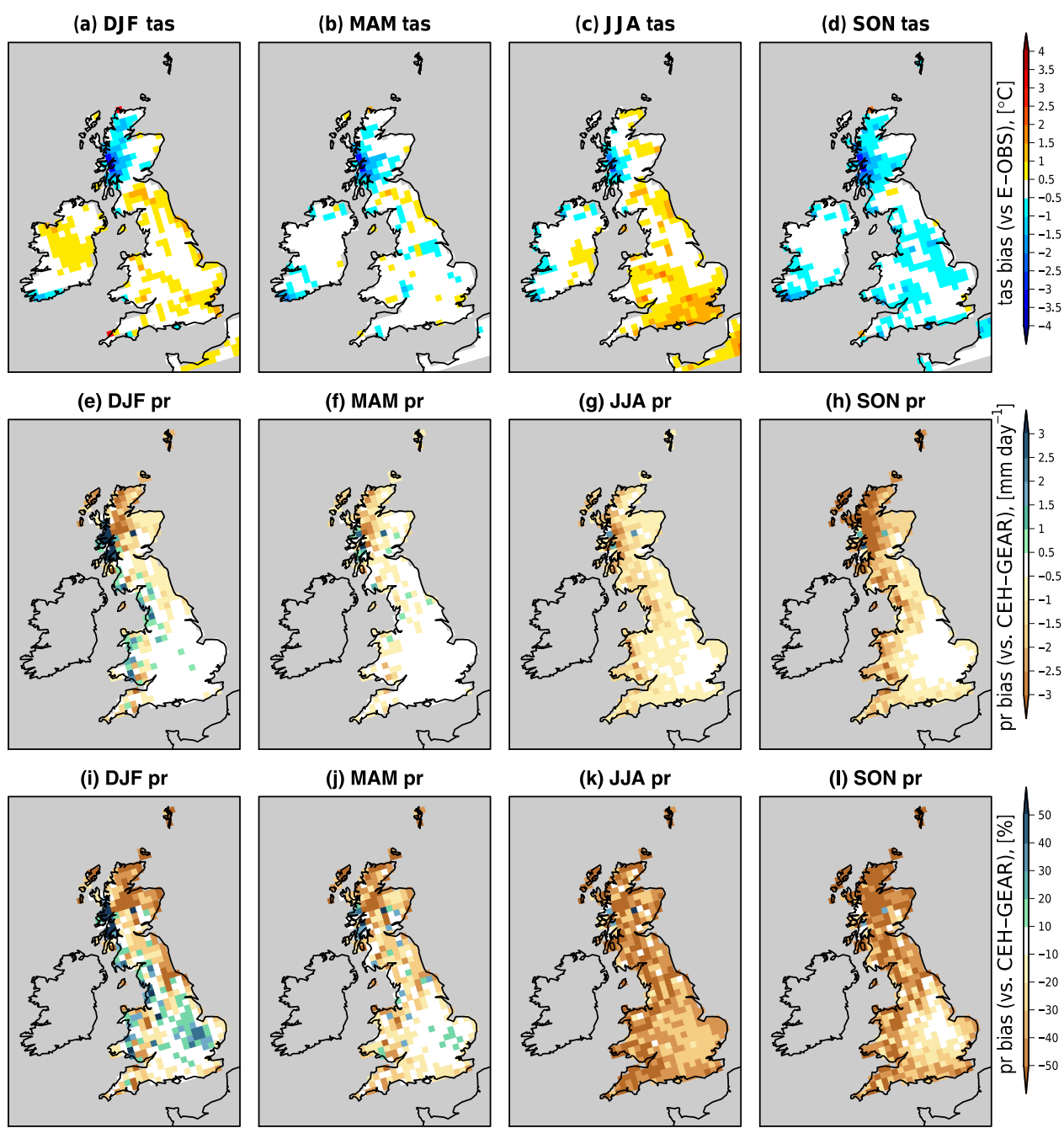

(j) MAM pr

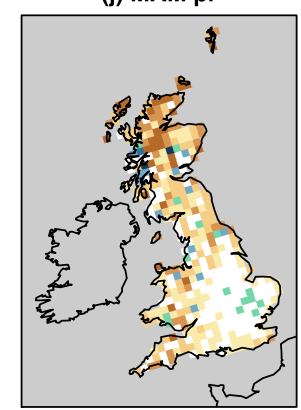

(k) JJA pr
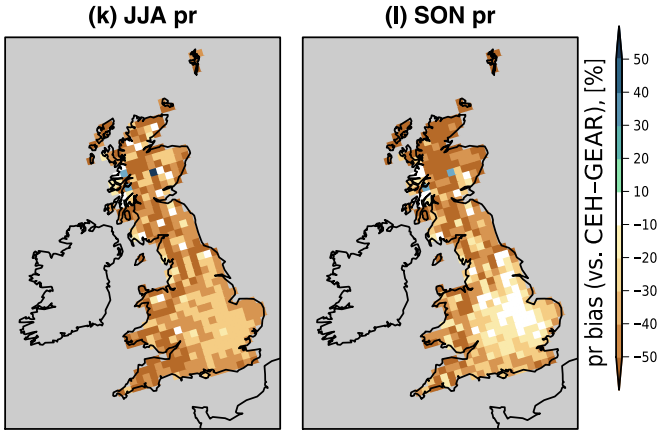

(m) DJF pepm

(n) MAM pepm
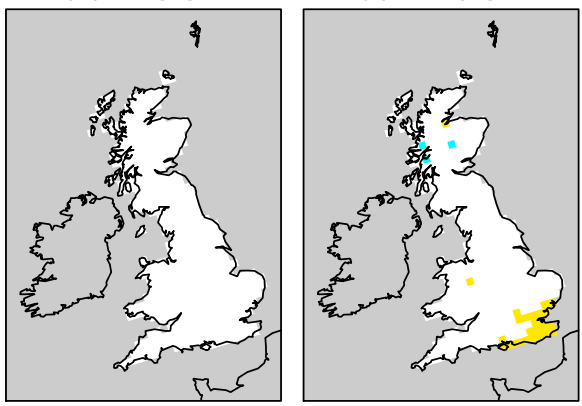

(o) JJA pepm
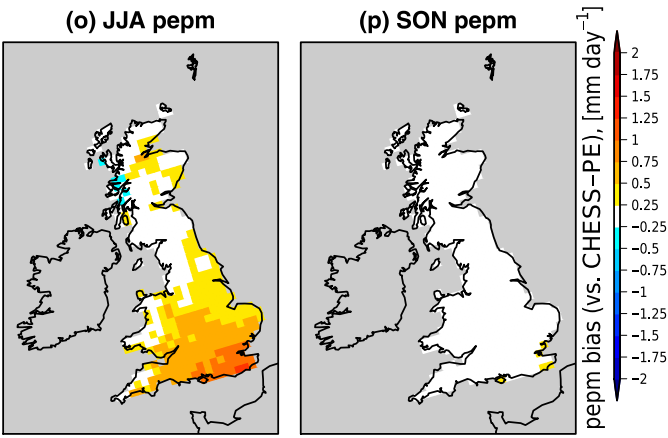

Figure 4. Seasonal biases in (a-d) mean surface air temperature, $(\mathbf{e}-\mathbf{h})$ precipitation in mm day $^{-1}$, (i-l) precipitation in $\%$ and (m-p) $E_{\text {pot }}$, for years 1961-2006. Each column is for a season as indicated in the labels.

an overestimation in the southern regions in summer (see also Fig. 4).

\subsection{Hydro-meteorological extremes}

In this section, the ability of the time series to represent the distribution of dry and wet extreme precipitation events is assessed, first on the scale of Great Britain averages for prolonged dry periods (Sect. 4.2.1) and then on the regional scale for prolonged dry periods and for shorter, high-precipitation events (Sect. 4.2.2). Comparison to CEHGEAR is done based on the overlapping years, i.e. 19002006, and using only data over Great Britain. 

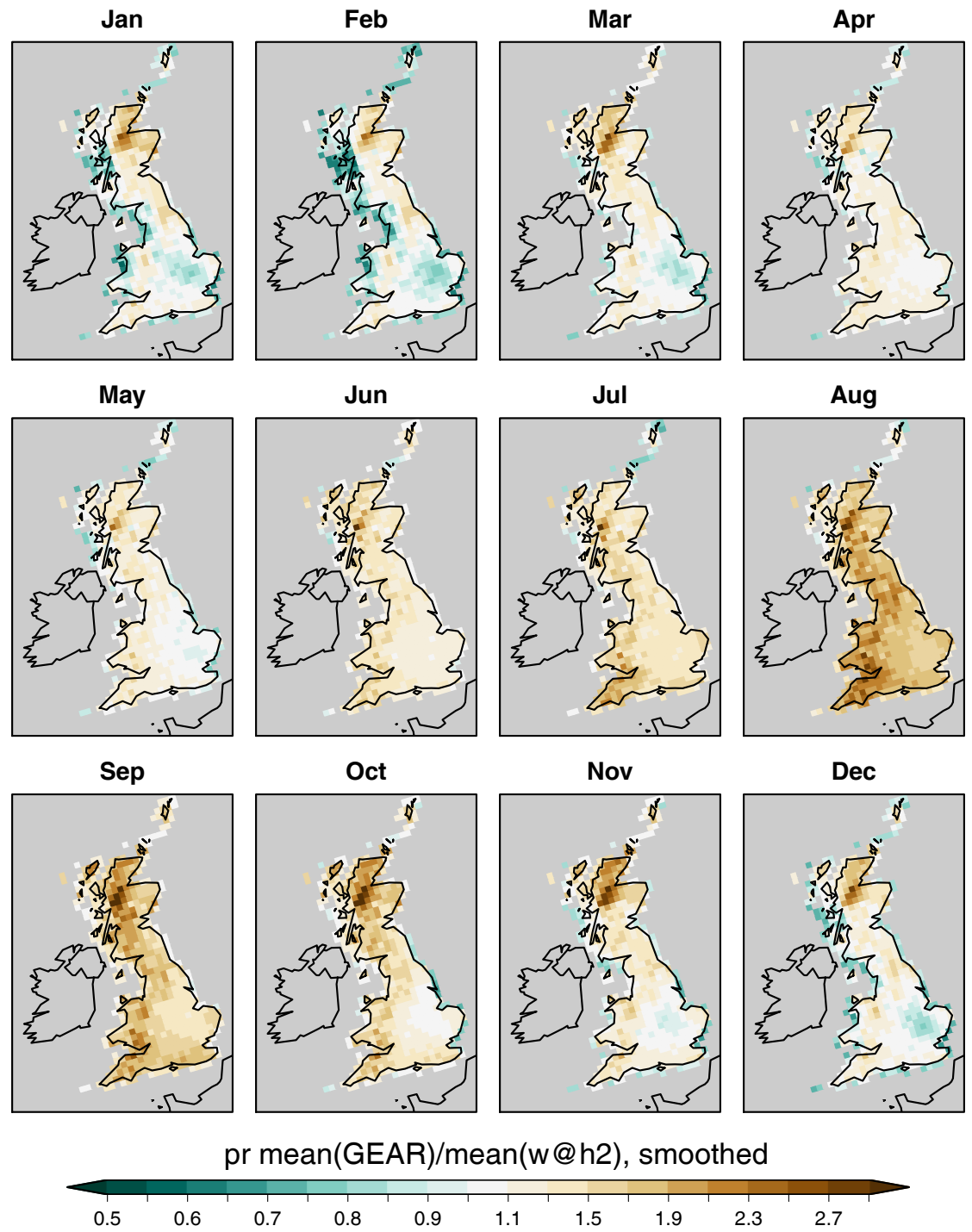

Figure 5. Bias-correction multiplicative factor applied to precipitation. A spatial smoothing was applied to the monthly ratios between observed (GEAR) and modelled (w@h2) 1961-2006 precipitation (see Fig. S5 for the unsmoothed ratio).

\subsubsection{Great Britain averaged dry events}

Figure $6 \mathrm{a}-\mathrm{d}$ show, for averaged values over Great Britain, return time plots of low precipitation (bias corrected) cumulated over a whole season. For w@h2, return values are displayed for each time series (grey) as well as when pooling all time series together (black). Overall, observed values lie within the range of the simulated values. However,w@h2 tends to overestimate winter low-precipitation values (i.e. not dry enough) but underestimate summer low-precipitation values (i.e. overestimated summer droughts). Nonetheless, even in those cases there are individual time series which look similar to the CEH-GEAR dataset, suggesting that natural variability could explain some of those apparent biases. The difficulty for climate models to represent low-frequency variability (Ault et al., 2012), an aspect that is by definition not improved by bias correction, could also play a role in this feature.

While short droughts do not usually pose a serious threat to Great Britain, prolonged periods of drought (e.g. multiannual) are more problematic. Therefore, we also show return time plots for multiple (one to four) consecutive hydrological years (October to September) on panels e-h of Fig. 6. On these longer timescales, the climate time series perform very well compared to the observed return values, which lie well within the ensemble. These results are encouraging for the MaRIUS project, as they suggest that the dataset may well represent precipitation accumulation over a long time period, which is the most critical aspect to British droughts. Noteworthy is a small overestimation of dryness at rare fre- 
(a) Seasonal, DJF

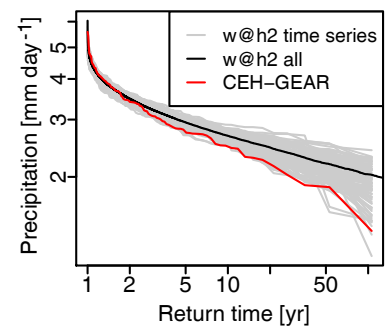

(e) 1 hydrological year

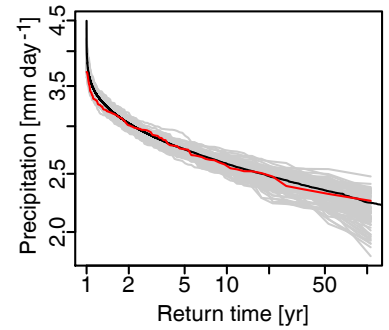

(b) Seasonal, MAM

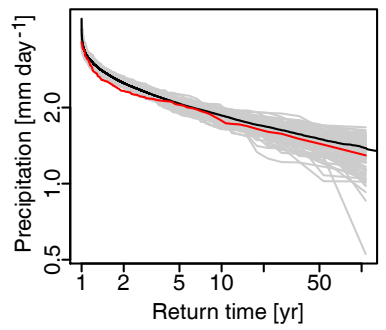

(f) 2 hydrological years

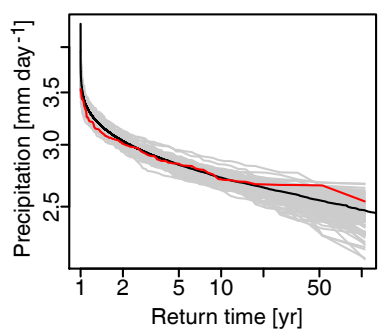

(c) Seasonal, JJA

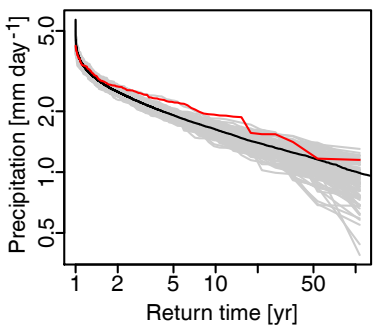

(g) 3 hydrological years

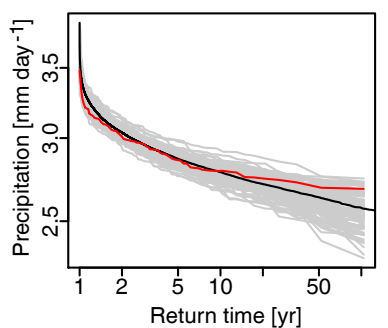

(d) Seasonal, SON

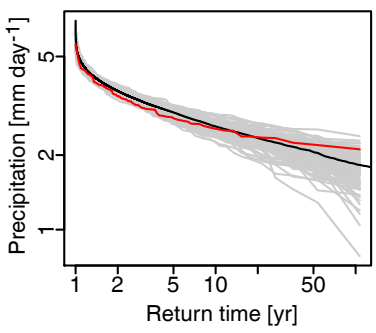

(h) 4 hydrological years

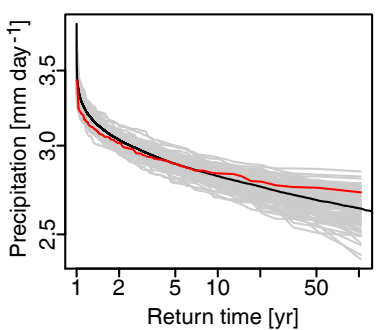

Figure 6. Return time plots of (a-d) low seasonal precipitation and (e-h) low precipitation accumulated in 1-4 consecutive hydrological years, for Great Britain averages from 1900 to 2006. (red) CEH-GEAR, (grey) individual w@h2 time series and (black) all w@ h2 time series pooled together. For each time series, seasonal or (multi-)year averages of precipitation were computed and spatially aggregated over Great Britain prior to the computation of return values.

quencies for long accumulation times (2 to 4 years), not present in the 1-year accumulated values, which suggests that in this case the climate model overestimates long-term precipitation persistence, unlike what has been shown for longer accumulation times (Ault et al., 2012). The next section goes into further details through validation on the regional scale.

\subsubsection{Regional extremes}

The analysis presented in the previous section was applied to regional averages of bias-corrected precipitation. To summarise the main findings, we focus on six selected UKCP09 river basin regions (Fig. 7; results for all 19 regions are shown in the Supplement) which are representative of various climate conditions within the country and include two regions particularly prone to droughts (Thames and Anglian). We focus on precipitation totals over multiple hydrological years and display, for each region, the distribution of 100 return values estimated from the individual time series as box plots, with the value estimated from the CEH-GEAR dataset overlaid as a white dot, for a number of return times (Fig. 8; see Fig. S10 for all regions). Overall, the observed values lie well within the range of modelled values, with a few exceptions: in some regions (e.g. North East Scotland) the time series slightly underestimate the values (i.e. overestimate drought intensity), while values are overestimated (i.e. dryness is underestimated) in the Western Highland region, probably due to the remaining bias after correction (see Sect. 4.1.3). For shorter durations, a similar plot for low seasonal precipitation is shown in Fig. S11 and allows dataset

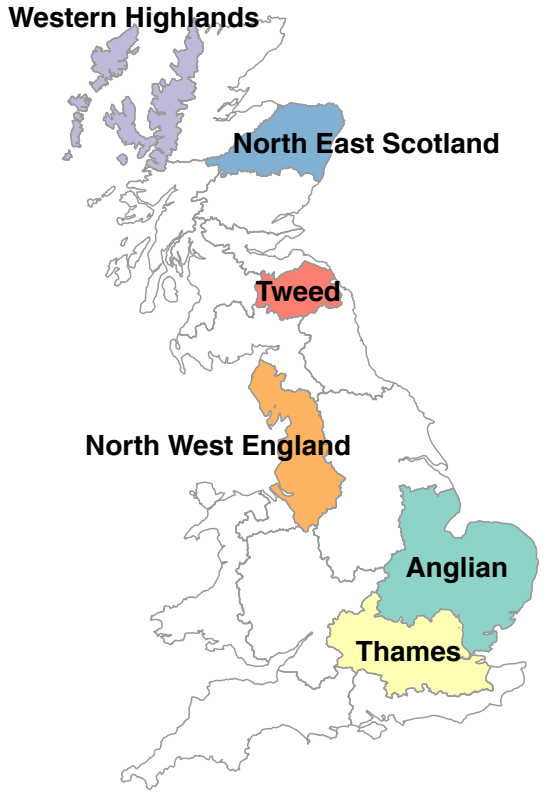

Figure 7. Subset of six river basin regions in Great Britain used in the analysis. All 19 UKCP09 river basin regions are shown in Fig. S3.

users to assess the performance of the dataset depending on their region and purpose.

Although the dataset was created within a project focusing on droughts, it could be used for other hydro-meteorological extremes such as floods. Therefore, we provide validation 

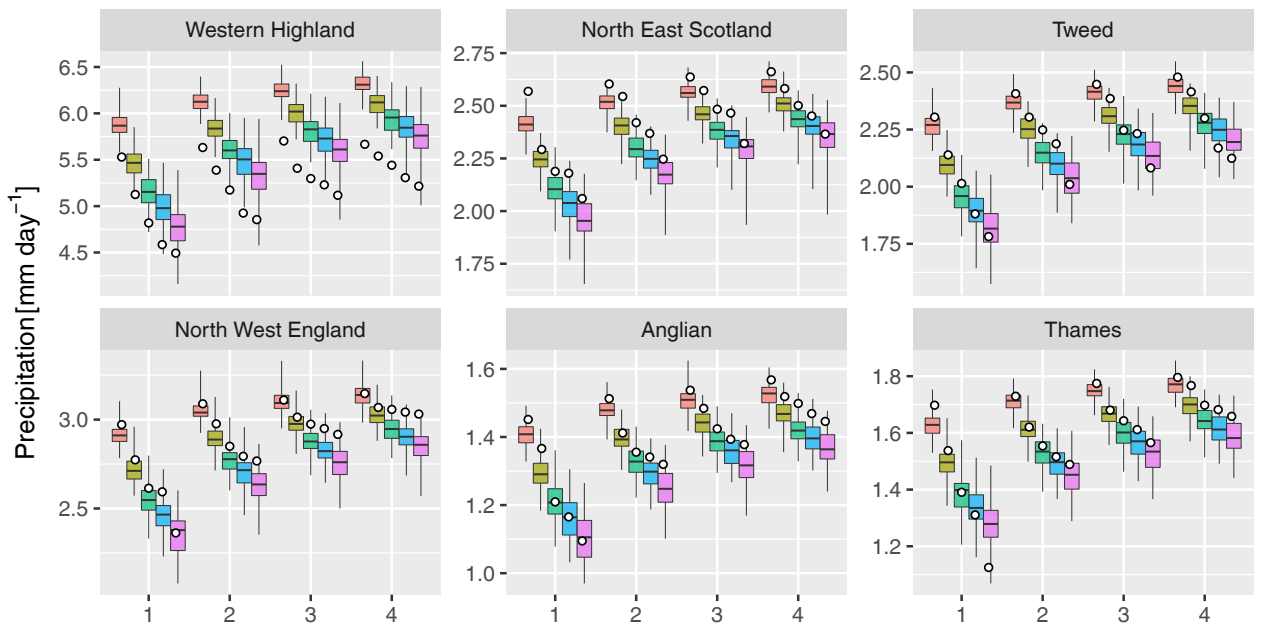

Return time

[years]

它 5

$\biguplus 10$

$\bigoplus 20$

岸 30

Number of hydrological years [years]

Figure 8. Return values of low precipitation accumulated over 1-4 hydrological years ( $x$ axis) in the 100 baseline time series (box plot) and in CEH-GEAR (white dot) for each region (panel), for return times of 5-50 years. See Fig. S10 for the plots for all regions and Fig. S11 for the same analysis on seasonal precipitation rather than hydrological years. Whiskers display the range from individual time series.
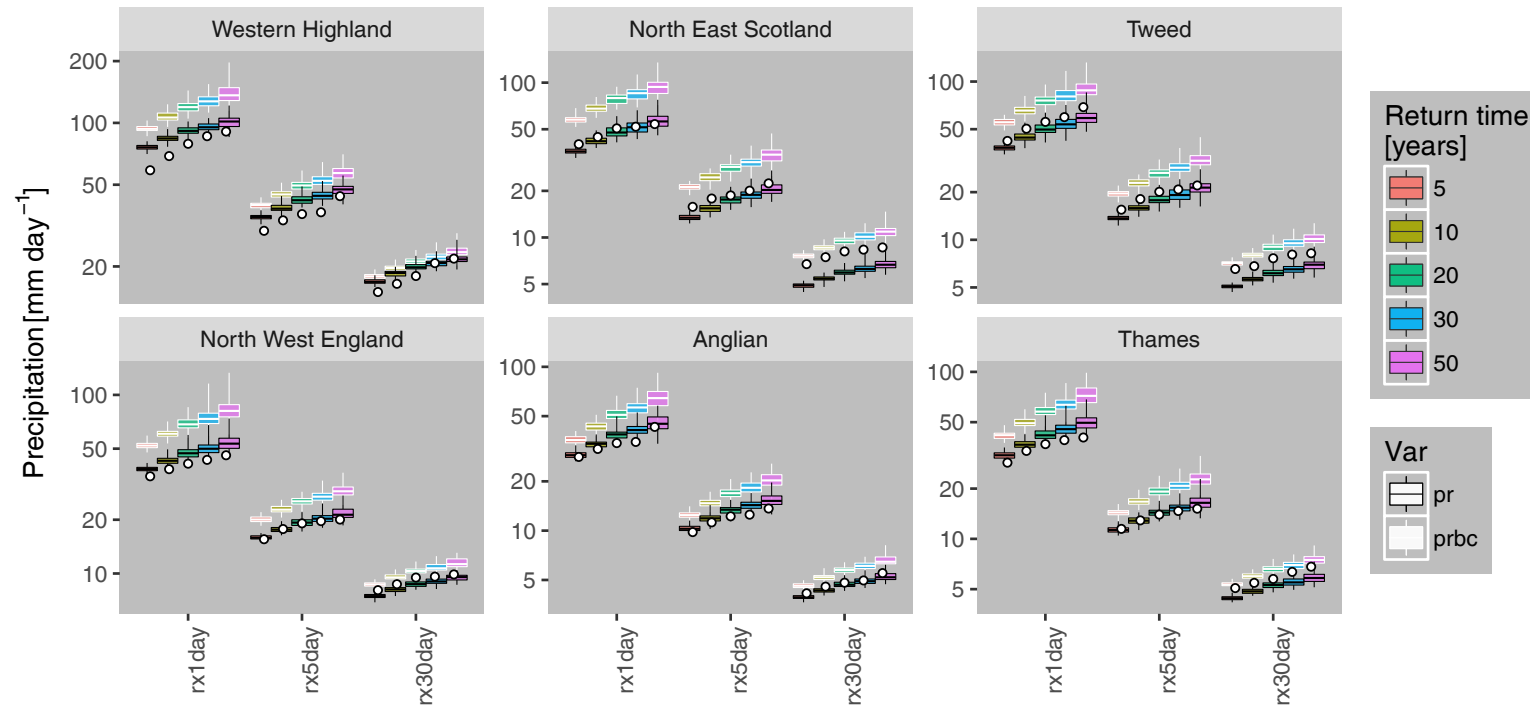

Figure 9. Return values of high-precipitation indices rx1day, rx5day and rx30day ( $x$ axis) in the 100 baseline time series (box plot) and in CEH-GEAR (white dot) for each region (panel), for return times of 5-50 years (colour). Bias-corrected precipitation data are boxed in white (raw precipitation data in black). Whiskers display the range from individual time series. Note that for these metrics, the raw precipitation data compares better to observations than bias-corrected values. See Fig. S12 for the plots for all regions.

of high-precipitation events at the regional level by focusing on total precipitation over a defined number $N$ of consecutive days, rx $N$ day for $N=1,5$ and 30 days. Figure 9 shows the return values for these three indices in a similar way as Fig. 8, but showing the results for both raw (uncorrected) and bias-corrected precipitation (see also Fig. S12 for all regions). The observed estimates are found to mostly lie within the spread of values obtained from the climate time series for raw precipitation but less so for bias-corrected precipitation. This suggests that the simple linear monthly bias correction that has been applied may not be appropriate for such events. An alternative hypothesis is that the model represents the processes related to high-precipitation formation relatively well (e.g. representation of UK-scale dynamical systems and thermodynamic processes, Schaller et al., 2016) but has more difficulties in representing longer-term persistence - a common feature of climate models (e.g. Ault et al., 2012). Therefore, we recommend the application of another bias-correction technique (e.g. quantile-quantile mapping) for studies on high-precipitation events. 

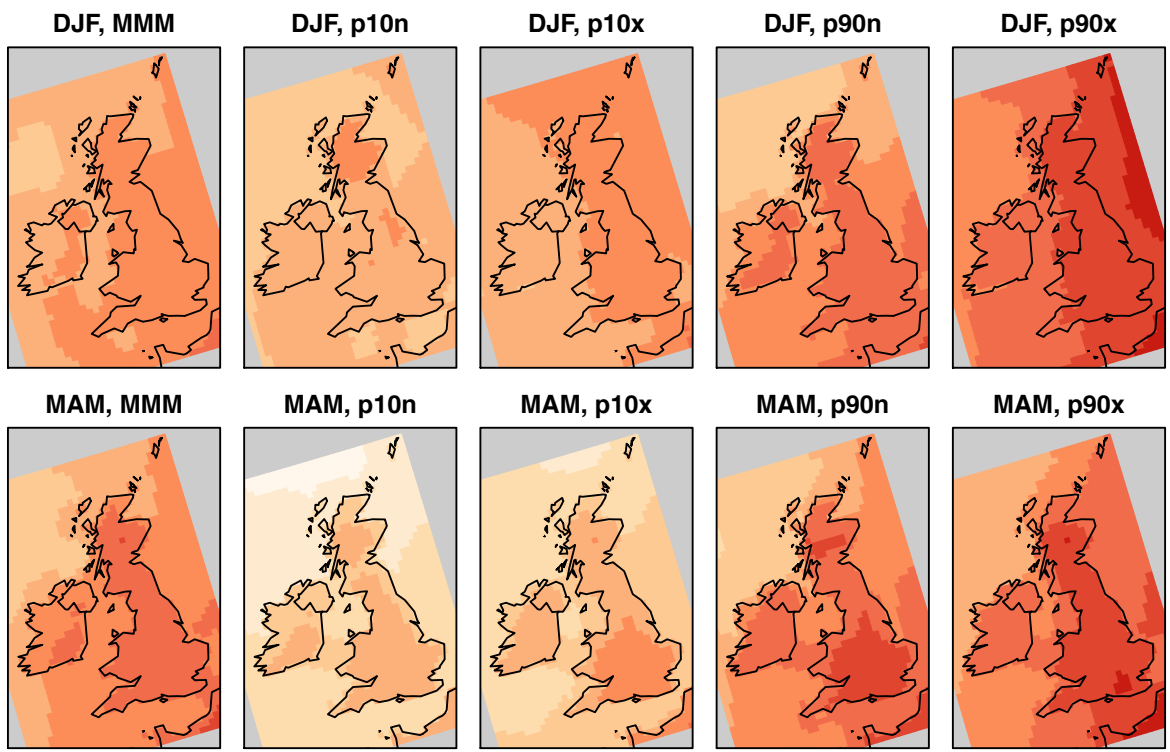

MAM, p90x
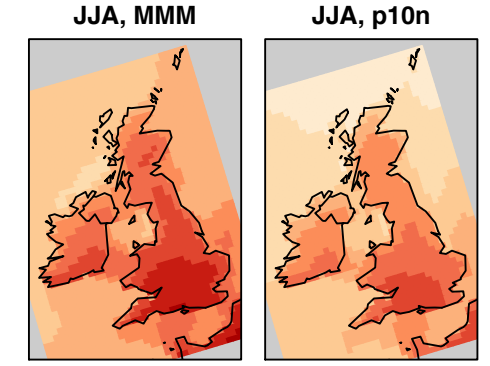

JJA, p10x

JJA, p90n
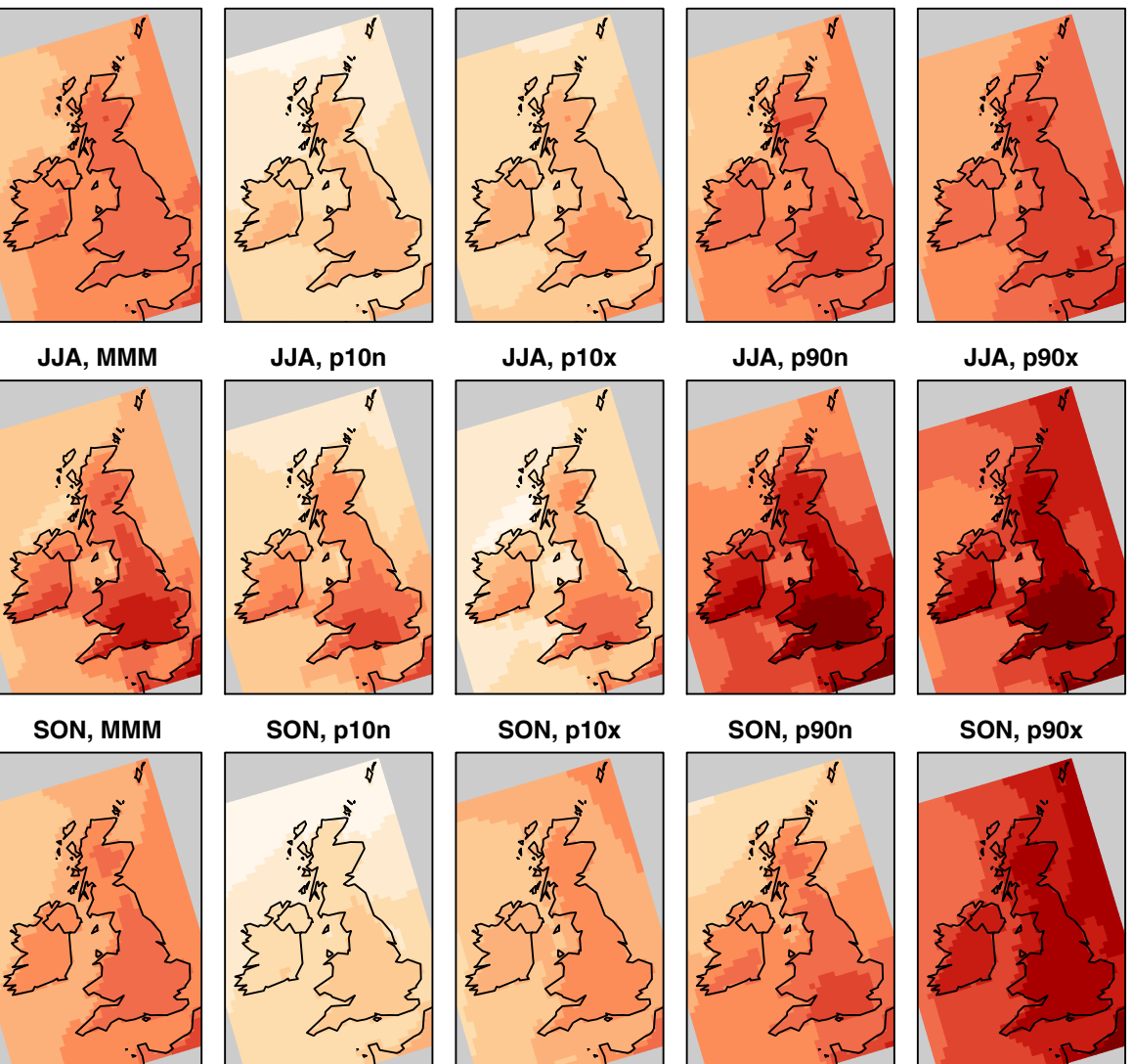

SON, p10n
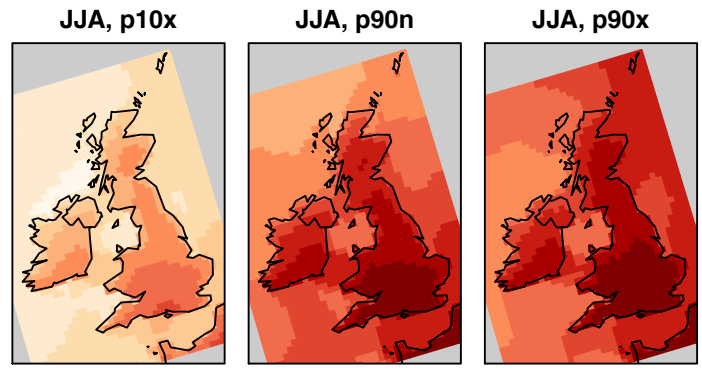

SON, p10x

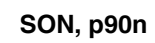

SON, p90x
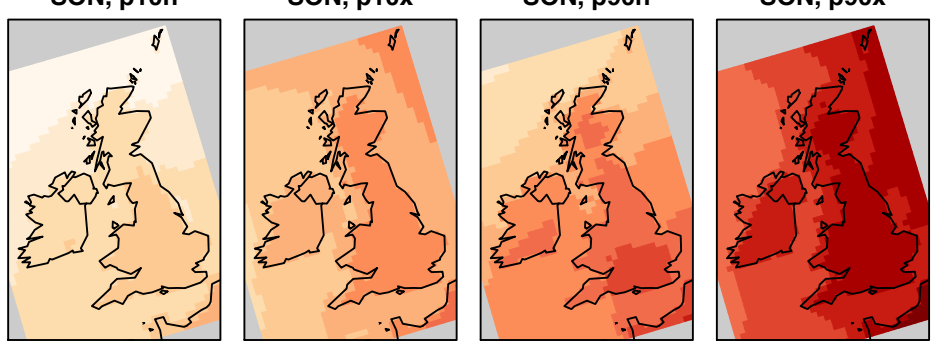

Near-surface air temperature: far future minus baseline $\left[{ }^{\circ} \mathrm{C}\right]$

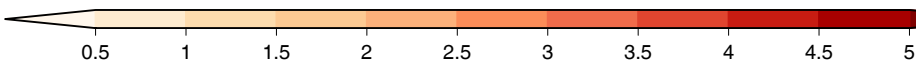

Figure 10. Difference in near-surface air temperature between far future and baseline (years 1975-2004 therein) for each season (row) and scenario (column). Hatching indicates grid cells with statistically non-significant changes at the $95 \%$ level according to a two-sided $T$ test (almost all grid cells are significant here). The corresponding figure for the near-future time slices is shown in Fig. S13.

It should be noted that the analysis of short-term events should be done on individual years separately rather than on the whole time series; for example rx5day should not lie at the transition from one year to the next since the weather is not strictly continuous (Sect. 3.4). For example, for rx5day, for each year, the first value is from 1-5 January and the last values from 25-30 December (the 360 days in a year are split into 12 months of 30 days), but it may not be appropriate to use the five pentads that range from 26 December-1 January to 30 December-4 January, in order to exclude undesirable concatenation of inconsistent weather systems.

\section{Future projections}

In this section, we display changes in the five far-future scenarios with respect to the 1975-2004 baseline, while corresponding changes for the near-future time slice are shown in the Supplement. First, changes in seasonal averages are 

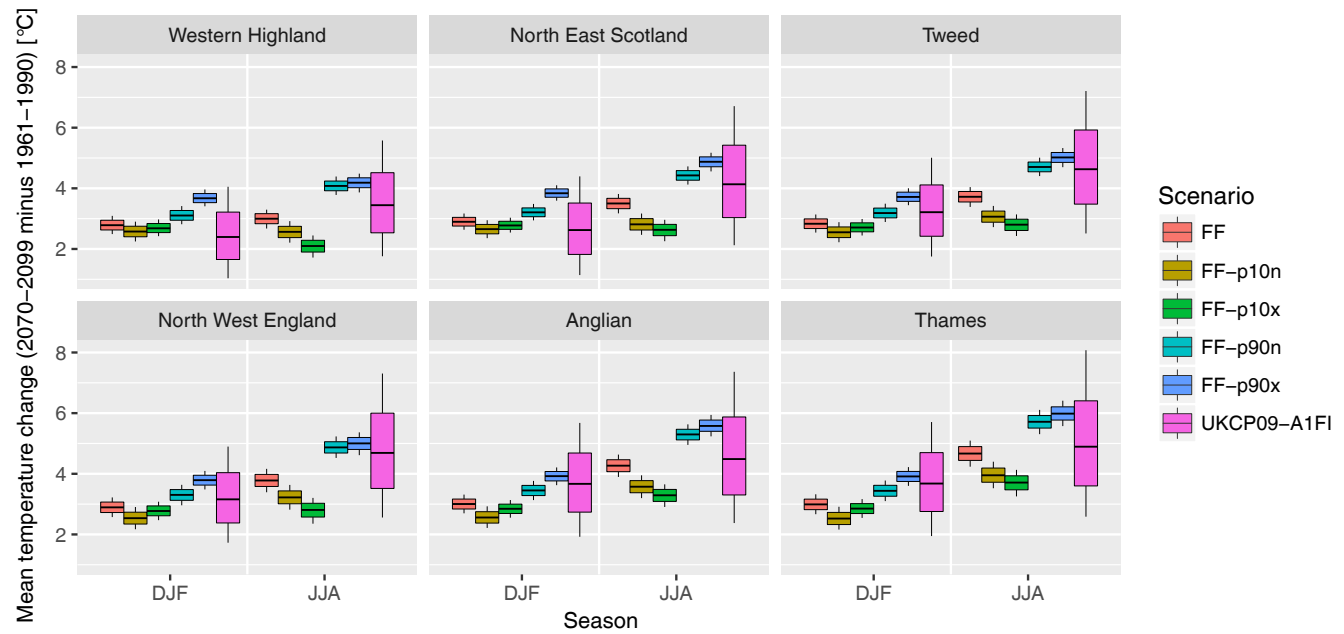

Figure 11. Comparison of temperature projections with UKCP09: for each region, boxes show changes (2070-2099 minus 1961-1990) in JJA (left boxes) and DJF (right boxes) in the five sets of MaRIUS time series and in UKCP09 (high emission scenario: SRES A1FI; 10 000 values available). Whiskers display the 10-90\% range from each group. See Fig. S14 for the plots for all regions.

displayed for the main variables, with a comparison to the UKCP09 projections (Murphy et al., 2009) at the regional level (Sect. 5.1). Indeed, UKCP09 data provide, among others, projected changes for a number of climate variables, time periods and climate scenarios. Second, changes in extremes are investigated at the regional level for prolonged low-precipitation periods and for short, high-precipitation extremes (Sect. 5.2).

\subsection{Changes in mean climate}

Figure 10 shows the changes in mean temperature in all farfuture scenarios with respect to the baseline (1975-2004) and for each season. All changes are statistically significant at the $95 \%$ level according to a two-sided $T$ test based on climatological values from individual time series for both time periods. Generally, temperature increases are highest in the scenarios with higher global mean SST increases (FF-p90x and FF-p90n) and lowest in the scenarios with low global mean SST increases (FF-p10n and FF-p10x). Consistently with UKCP09, temperature increases are largest in the southeast and in summer in all scenarios. Similar but lower increases in temperature are found in the near-future time slice (Fig. S13).

Figure 11 shows the distribution of all possible changes in temperature (i.e. from all combinations of the future time series with the baseline time series) and in UKCP09 (high emission scenario A1FI), relative to the years 1961-1990 for consistency with the UKCP09 data. The spread of UKCP09 values accounts for a wider range of uncertainty than in our time series, as it includes various climate models and parameter uncertainty. However, our various future scenarios generally cover the range of mean changes projected by the lat- est UK climate change scenarios (see also Fig. S14 for all regions).

The patterns of changes in seasonal mean precipitation (Fig. 12) highlight that, while in winter precipitation changes seem mostly related to global mean SST increases (as for temperature), summer precipitation changes are most sensitive to the North Atlantic SST gradient: time series FF-p10n and FF-p90n induce the smallest precipitation decreases, while FF-p10x and FF-p90x lead to the largest precipitation decrease. Thus, large SST gradients in the North Atlantic (as defined by the metric described in Sect. 3.2) lead to drier summer conditions. Note that the median scenario ("FF", called MMM in this figure for multi-model median) exhibits the CMIP5 median change in this feature, while the four other scenarios depict extreme cases in both direction and should hence be considered as sensitivity scenarios. The mechanisms through which SST influence precipitation may include the North Atlantic Oscillation (NAO), which has been shown to be influenced by SSTs in the Atlantic and to influence European weather (e.g. Woollings et al., 2015). It should be noted that changes in raw (without bias correction) precipitation are smaller in JJA, leading to an overall weaker drying in absolute terms. Most of the changes are statistically significant, apart from substantial areas in MAM and SON in individual cases and small areas in DJF. Similar patterns of change, but smaller in amplitude and thereby less robustly significant (especially in DJF), are identified in the near-future time slices (Fig. S15). By definition, relative changes are similar in both raw and bias-corrected precipitation as the same multiplicative factors are applied to both time periods.

Comparison of precipitation changes to UKCP09 (Fig. 13; see also Fig. S16 for all regions) reveals that the simulated time series lies on the dry end of the standard UK 

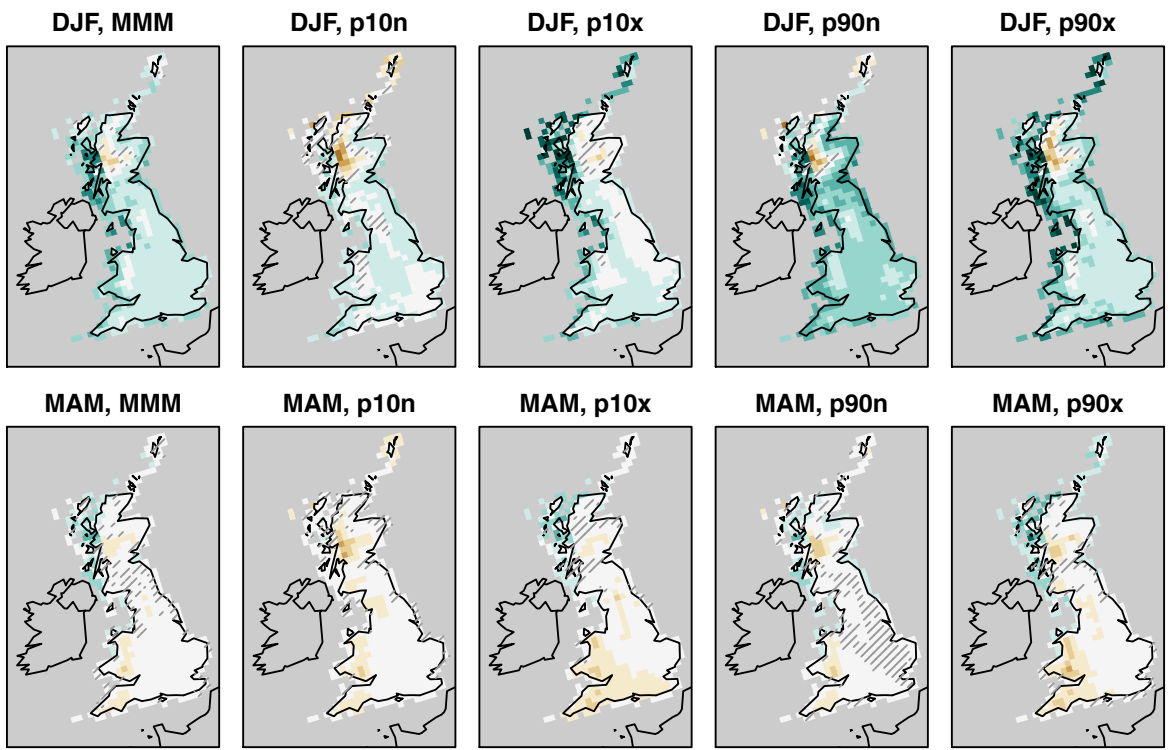

MAM, p90n

MAM, p90x
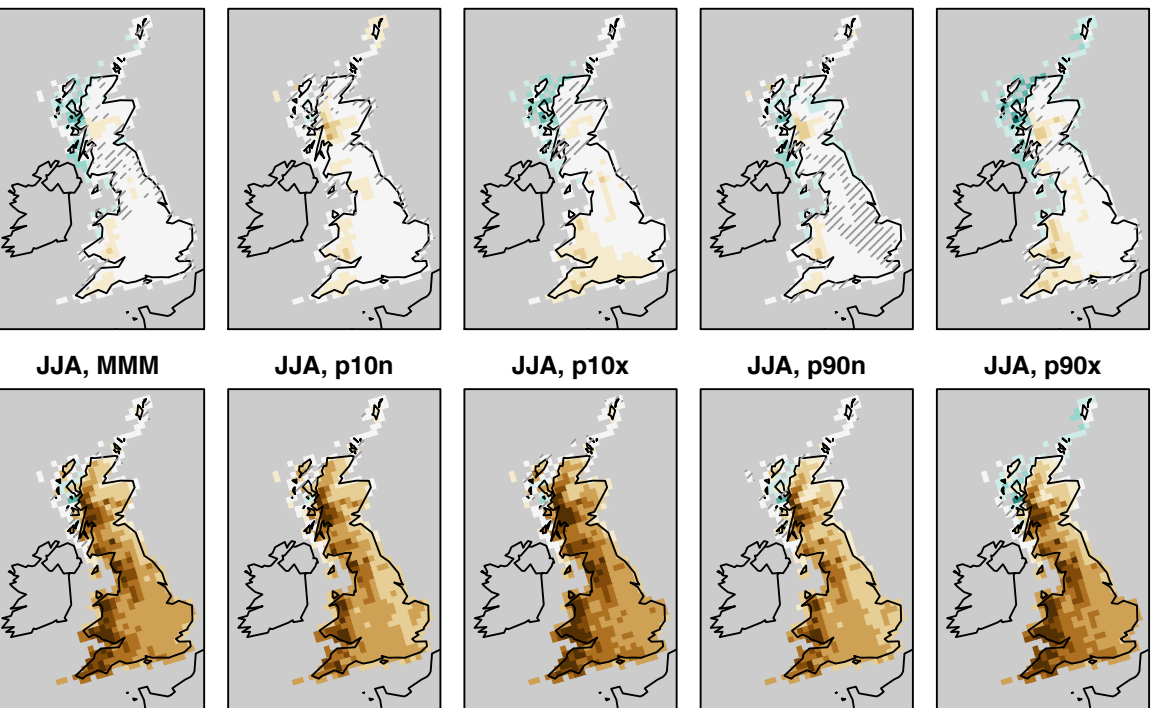

JJA, p10x

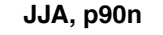

JJA, p90x
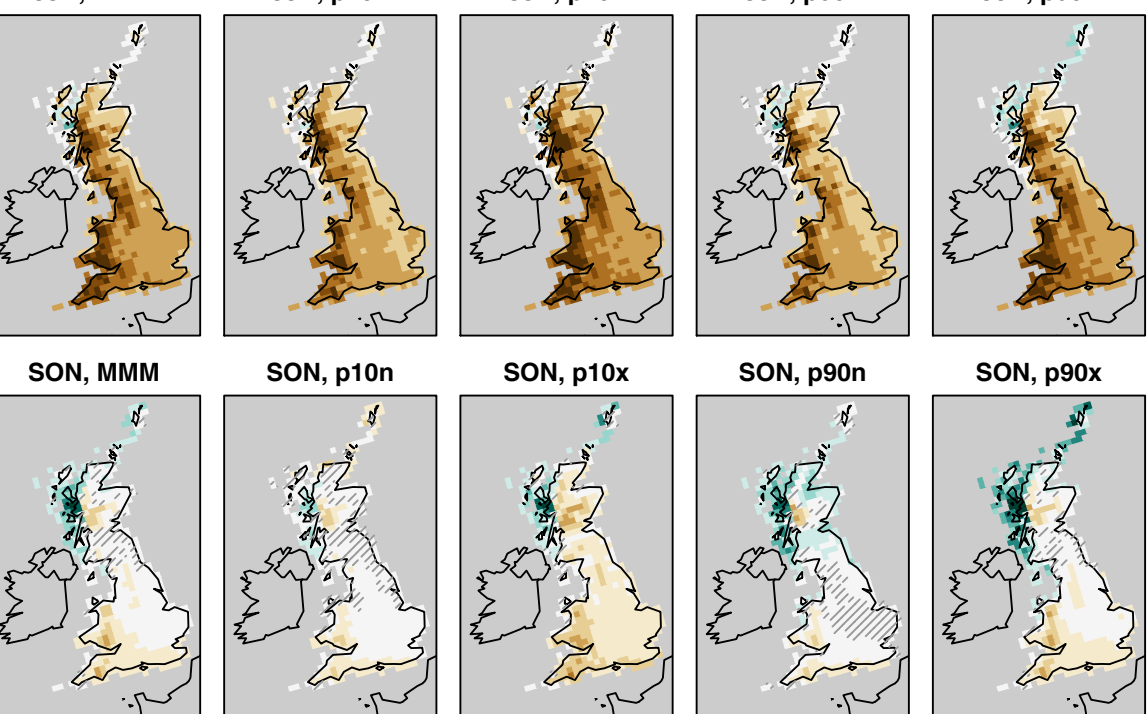

SON, p10n

SON, p10x

SON, p90n
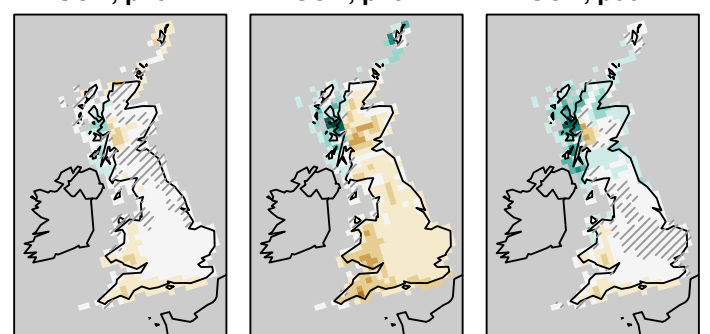

SON, p90x

Precipitation (BC): far future minus baseline $\left[\mathrm{mm} \mathrm{day}^{-1}\right]$

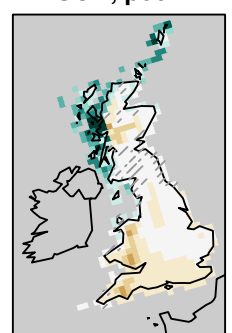

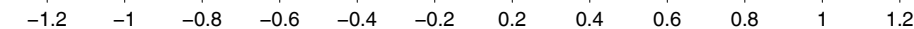

Figure 12. Same as Fig. 10 but for precipitation (bias corrected, prbc). Hatching indicates grid cells with statistically non-significant changes at the $95 \%$ level according to a two-sided $T$ test. The corresponding figure for the near-future time slices is shown in Fig. S15.

climate projections. The changes may thus be more similar to UKCP02, the previous UK climate scenarios, which were based on the same models that are used inw@h2. This feature is important to keep in mind, especially when analysing changes in drought. The dataset can thus be seen as an ideal test bed for dry conditions, but the actual future may potentially not be as dry as suggested by the climate time series presented in this paper. Note that in some cases, such as DJF in North East Scotland, changes are mostly not statistically significant in the sense that no change is included in the 5$95 \%$ range.

Finally, projected changes in seasonal mean $E_{\text {pot }}$ are displayed in Fig. 14, using the $E_{\text {pot }}$ formulation where stomatal resistance is adjusted to $\mathrm{CO}_{2}$ future concentrations. $E_{\mathrm{pot}}$ values substantially increase in summer and to a lower extent in autumn and spring. The changes are mostly driven by the global mean SST increase, similar to temperature and as one may expect due to the strong controls exerted by temperature on this variable. We note that not adjusting stom- 


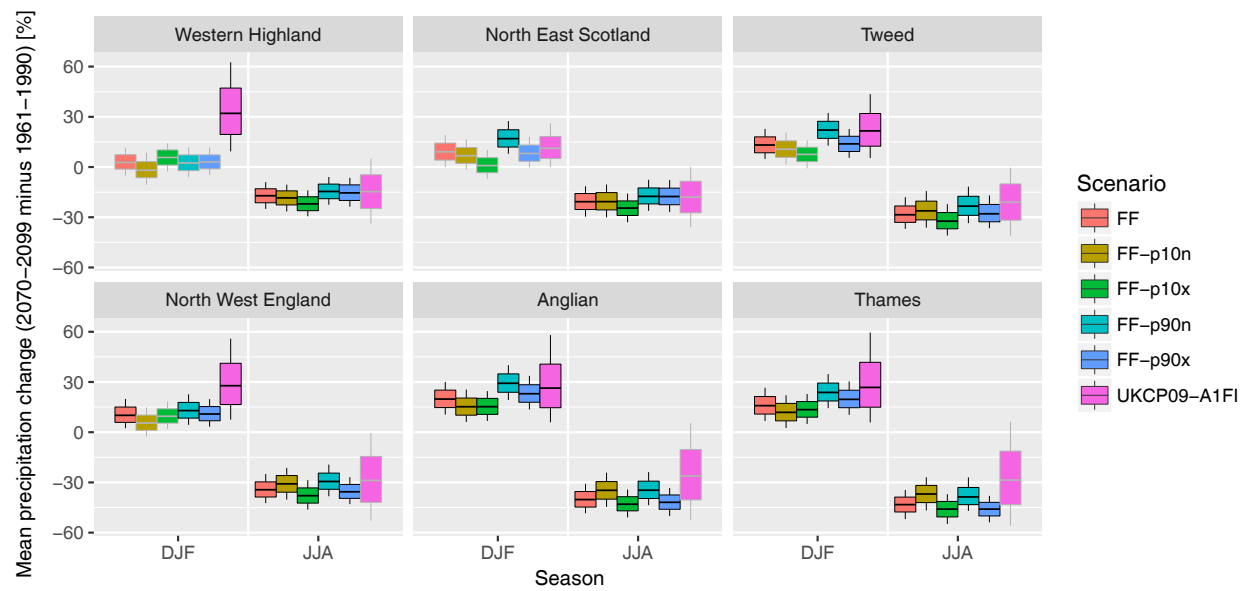

Figure 13. Same as Fig. 11 but for precipitation, in \%. Grey boxes indicate cases where 0 lies within the 5-95\% range. See Fig. S16 for the plots for all regions.

atal resistance to increased $\mathrm{CO}_{2}$ concentrations in the future (Fig. S17) would result in a significantly stronger increase in $E_{\text {pot }}$ and therefore recommend the use of pepm_adjrs for future analyses to prevent overestimating increases in drought. As for temperature and precipitation, the near-future time slice displays changes that are qualitatively similar to those of the far future but smaller in amplitude (Figs. S18 and S19).

\subsection{Changes in hydro-meteorological extremes}

As for the validation of extremes done in Sect. 4.2.2, we concentrate on extremes of low precipitation cumulated over a number of consecutive hydrological years and on highprecipitation extremes cumulated over a small number of consecutive years.

Figure 15 displays the 10-year return value (i.e. third highest value in each 30-year time series) of low precipitation accumulated over 2 hydrological years (see Fig. S20 for all regions). The distribution of the values estimated from each time series is shown for the baseline and for each far-future scenario, whereby boxes for future scenarios whose mean value does not significantly differ from the baseline according to a two-sided $T$ test at the $95 \%$ level are displayed in grey. Generally, a strong drying is found; i.e. 10-year dry events are getting more intense. In most regions, most of the difference between the individual future scenarios (i.e. SST warming patterns) appears to be related to the North Atlantic SST pattern, rather than to global mean SSTs. This suggests, given the findings of Fig. 12, that the summer response may drive the changes in longer droughts ( 2 hydrological years in this case).

Similarly, Fig. 16 displays the change in 10-year return value of rx5day, using uncorrected precipitation data since these perform better than bias corrected for highprecipitation events as highlighted in Sect. 4.2.2. Highprecipitation extremes are expected to increase in intensity in most scenarios, except in those with low global mean sea surface temperature increase (FF-p10n and FF-p10x) in some regions, despite a smaller signal-to-noise ratio induced by the sampling of 10-year return values from 30-year time series. Unlike for drought, global mean SST increases appear to be the main factor leading to the response in extreme high precipitation, consistently with the Clausius-Clapeyron relationship (higher SST leading to higher evaporation and higher moisture content) and with the current understanding of atmospheric thermodynamics (e.g. Schaller et al., 2016). Results for all regions are shown in Fig. S21.

In the near-future time slice, similar but smaller changes are found for low precipitation (Fig. S22); i.e. an increase in drought severity may already be expected in this time period. However, for high-precipitation events (rx5day, Fig. S23), the increase is very small in this time period and is in most cases not statistically significant.

\section{Conclusions}

This paper presents a new set of climate projections for the United Kingdom, based on a regional climate model driven by a global atmospheric model which accounts for uncertainty in the climate system response by sampling a range of changes in the ocean state from CMIP5 models. The dataset includes a large number of spatio-temporally consistent time series for the recent past (1900-2006) and for the near and far future (30-year time slices ending in the middle and at the end of the 21st century, respectively). Future projections follow the assumption of a high greenhouse gas emission scenario (RCP8.5), allowing the testing of the sensitivity of the system to relatively large changes in climate forcing. The analysis could be repeated for alternative RCP scenarios.

An advantage of this dataset compared to previous UK climate projections is the availability of a large number of spa- 

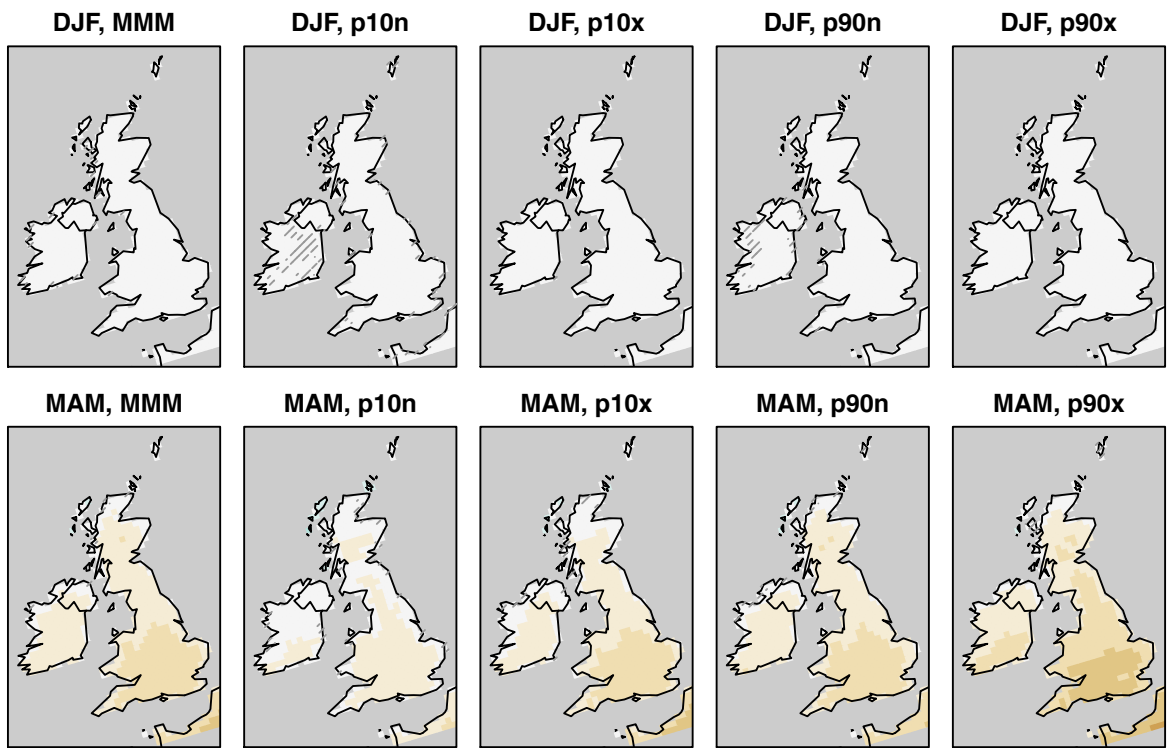

MAM, p90x
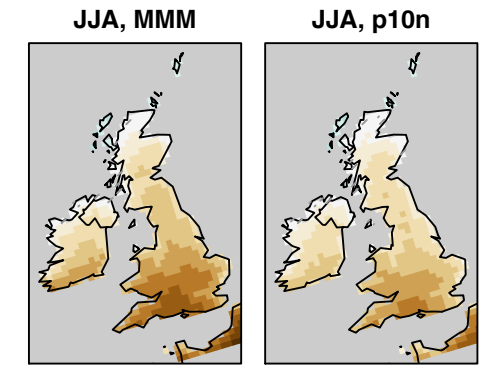

JJA, p10x

JJA, p90n
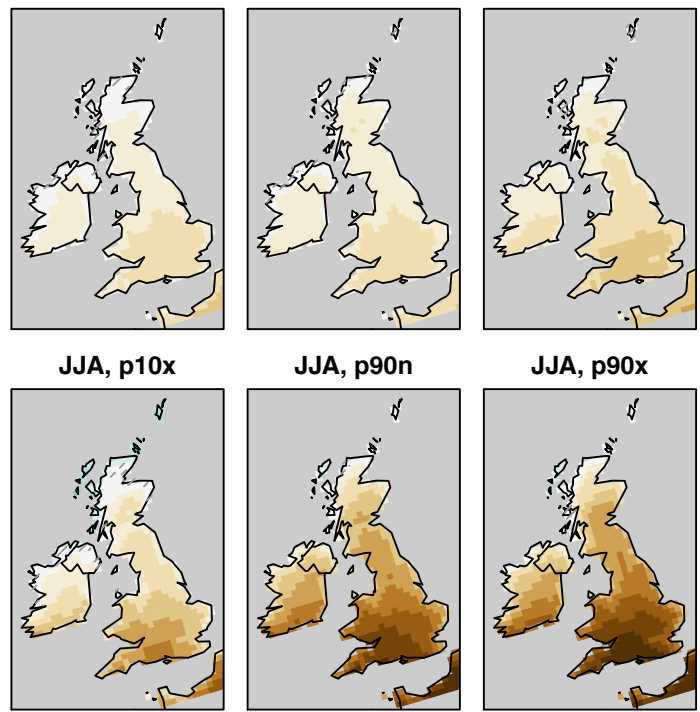

JJA, p90x

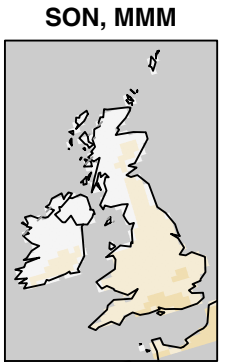

SON, p10n

SON, p10x

SON, p90n
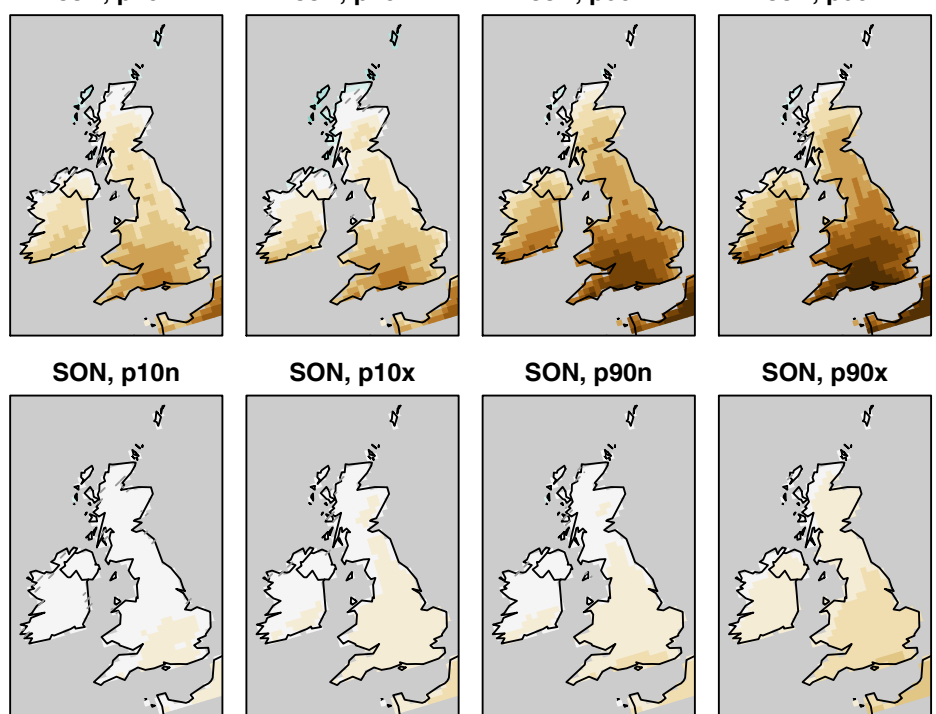

SON, p90x

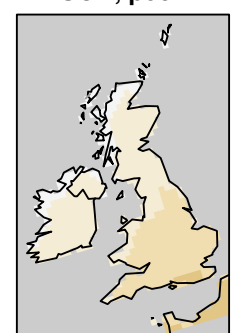

pepm (adj r_s): far future minus baseline $\left[\mathrm{mm}\right.$ day $\left.^{-1}\right]$

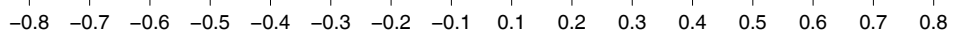

Figure 14. Same as Fig. 10 but for $E_{\text {pot }}$ (with stomatal resistance adjusted to $\mathrm{CO}_{2}$ concentration; see Fig. $\mathrm{S} 17$ for the changes when stomatal resistance is kept constant). Hatching indicates grid cells with statistically non-significant changes at the $95 \%$ level according to a two-sided $T$ test. The corresponding figures for the near-future time slices are shown in Figs. S18 and S19.

tially consistent time series, which is important for risk analysis of hydrological phenomena that are sensitive to spatial and temporal variability. Moreover, the availability of a large number of time series allows us to better account for internal variability (albeit only the atmospheric part of it), which has been shown to be a main source of uncertainty in climate projections (e.g. Deser et al., 2014). This comes at the expense of essentially using only one climate model (global and regional). However, in an effort to sample as wide a range of conditions as possible, part of the uncertainty in the climate system response is incorporated by using a range of projected changes in ocean states from CMIP5 models.

One of the challenges associated with the chosen approach is the generation of continuous time series from a large set of single-year simulations. A novel methodology has been developed and validated, which is based on identifying simulations with the best matching soil moisture patterns to ensure continuity in slowly evolving hydro-meteorological 


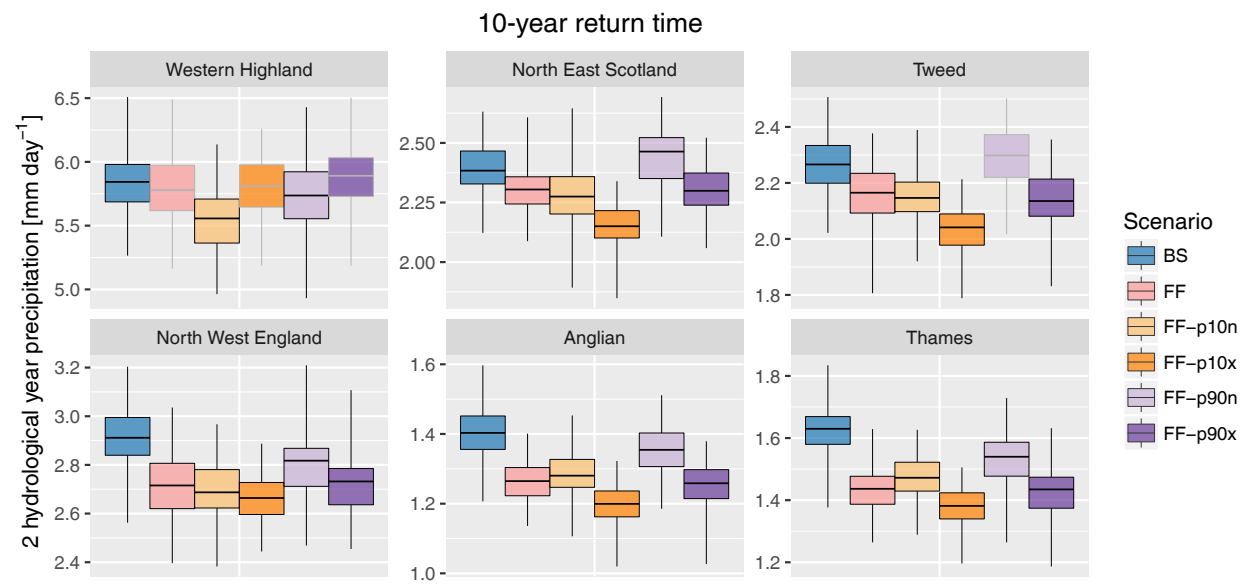

Figure 15. Distribution of return values of the 10-year event for low precipitation on two consecutive hydrological years (box plot) for each region (panel) and scenario (colour). Whiskers display the range from individual time series. Grey boxes for future scenarios indicate statistically non-significant change in mean return value with respect to the baseline at the $95 \%$ level according to a two-sided $T$ test. See Fig. S20 for the plots for all regions; the corresponding figure for the near-future time slices is shown in Fig. S21.
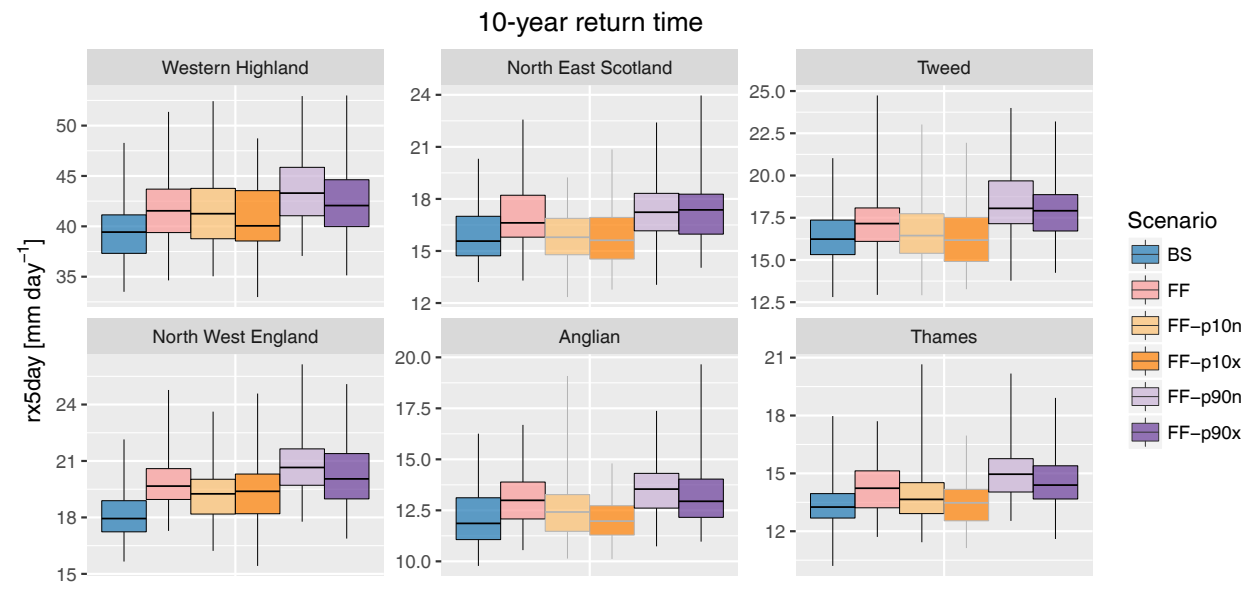

Figure 16. Distribution of return values of the 10-year event for rx5day (box plot) for each region (panel) and scenario (colour), using raw precipitation data (i.e. not bias corrected). Whiskers display the range from individual time series. Grey boxes for future scenarios indicate statistically non-significant change in mean return value with respect to the baseline at the $95 \%$ level according to a two-sided $T$ test. See Fig. S22 for the plots for all regions; the corresponding figure for the near-future time slices is shown in Fig. S23.

variables, with the ocean state being continuous by definition as it is prescribed. This methodology is shown to be a promising tool for the application of weather@home to long-lasting extreme events such as drought.

The created time series are shown to represent mean climate and extreme hydro-meteorological events relatively well, after correcting for a substantial precipitation bias. We did not bias-correct potential evaporation but we strongly recommend data users to carefully assess possible impacts of these biases on their results, particularly with respect to drought analysis in the southern part of the UK. For highprecipitation extremes, the better performance of raw (uncorrected) precipitation output (compared to bias-corrected precipitation) highlights that while the choice of a simple linear bias correction might be appropriate with respect to mean, seasonality, and perhaps accumulated totals over a few months, analysis of short-duration hydro-meteorological extremes might require the application of a more sophisticated bias-correction methodology. In addition, the application of a bias-correction technique to climate model output cannot correct for interannual to decadal climate variability, which is known to be poorly captured in current stateof-the-art climate models (e.g. Ault et al., 2012). This issue could potentially lead to an underestimation of the risk of multi-decadal droughts (Ault et al., 2014). As with any model-based dataset, an evaluation of metrics relevant to the processes investigated is recommended in order to choose a 
suitable set of variables and, where required, to apply a suitable bias-correction technique.

The projected changes in climate, using five SST warming patterns, mostly cover the temperature range of UKCP09 but tend to lie on the dry end of the precipitation changes obtained in UKCP09. Prolonged periods of low precipitation are projected to become more frequent and intense, as are short-duration high-precipitation events. The analysis of the projected changes also provides some useful insights into the oceanic drivers. Some variables are most sensitive to the overall (global) SST warming amplitude (e.g. temperature, winter precipitation) while others are most sensitive to the SST gradient in the North Atlantic (e.g. summer precipitation). These results also suggest that the future seasonal cycle may depend on the oceanic response to climate change, in particular with respect to the North Atlantic, and oceanatmosphere interactions.

In the context of the MaRIUS project, these time series are being used as input to hydrological, ecological and agricultural models, among others. Combining these outputs with, for example, water resource models will allow for an in-depth investigation of the drivers of water scarcity in the UK and for the identification of suitable adaptation measures. Additionally, the availability of a large number of time series, driven by different SST patterns, will allow the identification of the oceanic, meteorological and hydrological drivers of drought in the UK in subsequent analyses. The spatiotemporal structure of drought in the UK, and how it may change in the future, will also be investigated as part of MaRIUS.

Data availability. The dataset presented in this paper is available on the Centre for Environmental Data Analysis (CEDA) platform (Guillod et al., 2017b; see https://doi.org/10.5285/0cea8d7aca57427fae92241348ae9b03).

Data, in NetCDF format, are provided as yearly files for each simulation and with a table indicating the simulations corresponding to each time series and year and include the variables listed in Table 3 for all the time series for each scenario (Table 2). A pdf file documenting the format and structure is available as part of the dataset.

Supplement. The supplement related to this article is available online at: https://doi.org/10.5194/hess-22-611-2018-supplement.

Author contributions. BPG designed the modelling experiments with input from RGJ, NRM, JWH and MRA. NRM created the future SSTs and sea ice boundary conditions. ALK assisted BPG with the $E_{\text {pot }}$ computation. BPG, GC, SJD, RGJ, GB and JF designed and evaluated the bias-correction methodology. SNS and DCHW managed the climateprediction.net infrastructure and model simulations thereon. BPG ran the model simulations, designed the stitch- ing methodology, analysed the data and wrote the paper. All coauthors provided comments on the text.

Competing interests. The authors declare that they have no conflict of interest.

Acknowledgements. This work was undertaken within the MaRIUS project: Managing the Risks, Impacts and Uncertainties of droughts and water Scarcity, funded by the Natural Environment Research Council (NERC), and undertaken by a project team spanning the University of Oxford (NE/L010364/1), University of Bristol (NE/L010399/1), Cranfield University (NE/L010186/1), the Met Office, and the Centre for Ecology and Hydrology (NE/L010208/1). We acknowledge the E-OBS dataset from the EU-FP6 project ENSEMBLES (http://ensembles-eu.metoffice.com) and the data providers in the ECA\&D project (http://www.ecad.eu). We also acknowledge the CEH-GEAR and the CHESS-PE datasets provided by the Centre for Ecology and Hydrology (https://eip.ceh.ac.uk). We are grateful to CEDA (Centre for Environmental Data Analysis, NERC) and their Jasmin analysis platform (Lawrence et al., 2013) on which data analysis has been done. We would like to thank our colleagues at the Oxford eResearch Centre: Peter Uhe, Andy Bowery and Mamun Rashid for their technical expertise. We would also like to thank the Met Office Hadley Centre PRECIS team for their technical and scientific support for the development and application of weather@home. Finally, we would like to thank all of the volunteers who have donated their computing time to climateprediction.net and weather@home.

Edited by: Luis Samaniego

Reviewed by: Eleanor Blyth and one anonymous referee

\section{References}

Allen, M.: Do-it-yourself climate prediction, Nature, 401, 642-642, https://doi.org/10.1038/44266, 1999.

Ault, T. R., Cole, J. E., and St. George, S.: The amplitude of decadal to multidecadal variability in precipitation simulated by state-of-the-art climate models, Geophys. Res. Lett., 39, https://doi.org/10.1029/2012GL053424, L21705, 2012.

Ault, T. R., Cole, J. E., Overpeck, J. T., Pederson, G. T., and Meko, D. M.: Assessing the Risk of Persistent Drought Using Climate Model Simulations and Paleoclimate Data, J. Climate, 27, 75297549, https://doi.org/10.1175/JCLI-D-12-00282.1, 2014.

Azzalini, A.: The skew-normal distribution and related multivariate families, Scand. J. Stat., 32, 159-188, 2005.

Deser, C., Phillips, A. S., Alexander, M. A., and Smoliak, B. V.: Projecting North American Climate over the Next 50 Years: Uncertainty due to Internal Variability, J. Climate, 27, 2271-2296, https://doi.org/10.1175/JCLI-D-13-00451.1, 2014.

Guillod, B. P., Orlowsky, B., Miralles, D. G., Teuling, A. J., and Seneviratne, S. I.: Reconciling spatial and temporal soil moisture effects on afternoon rainfall, Nat. Commun., 6, 7443, https://doi.org/10.1038/ncomms7443, 2015.

Guillod, B. P., Jones, R. G., Bowery, A., Haustein, K., Massey, N. R., Mitchell, D. M., Otto, F. E. L., Sparrow, S. N., 
Uhe, P., Wallom, D. C. H., Wilson, S., and Allen, M. R.: weather@home 2: validation of an improved global-regional climate modelling system, Geosci. Model Dev., 10, 1849-1872, https://doi.org/10.5194/gmd-10-1849-2017, 2017a.

Guillod, B. P., Jones, R. G., Kay, A. L., Massey, N. R., Sparrow, S., Wallom, D. C., and Wilson, S. S.: Managing the Risks, Impacts and Uncertainties of drought and water Scarcity (MaRIUS) project: Large set of potential past and future climate time series for the UK from the weather@home2 model, Centre for Environmental Data Analysis, available at: https://doi.org/10.5285/0cea8d7aca57427fae92241348ae9b03 (last access: 23 January 2018), 2017 b.

Haylock, M. R., Hofstra, N., Klein Tank, A. M. G., Klok, E. J., Jones, P. D., and New, M.: A European daily highresolution gridded data set of surface temperature and precipitation for 1950-2006, J. Geophys. Res., 113, D20119, https://doi.org/10.1029/2008JD010201, 2008.

Hirschi, M., Seneviratne, S. I., Alexandrov, V., Boberg, F., Boroneant, C., Christensen, O. B., Formayer, H., Orlowsky, B., and Stepanek, P.: Observational evidence for soil-moisture impact on hot extremes in southeastern Europe, Nat. Geosci., 4, 17-21, https://doi.org/10.1038/ngeo1032, 2011.

Hornik, K.: A CLUE for CLUster Ensembles, J. Stat. Softw., 14, 1-25, https://doi.org/10.18637/jss.v014.i12, 2005.

Hornik, K.: clue: Cluster ensembles, available at: https://CRAN. R-project.org/package=clue (last access: 25 October 2017), R package version 0.3-51, 2016.

Hough, M. N. and Jones, R. J. A.: The United Kingdom Meteorological Office rainfall and evaporation calculation system: MORECS version 2.0 - an overview, Hydrol. Earth Syst. Sci., 1, 227-239, https://doi.org/10.5194/hess-1-227-1997, 1997.

IPCC: Climate Change 2013: Working Group I Contribution to the IPCC Fifth Assessment Report: The Physical Science Basis, Cambridge University Press, Cambridge, United Kingdom and New York, NY, USA, 2013.

Keenan, T. F., Hollinger, D. Y., Bohrer, G., Dragoni, D., Munger, J. W., Schmid, H. P., and Richardson, A. D.: Increase in forest water-use efficiency as atmospheric carbon dioxide concentrations rise, Nature, 499, 324-327, https://doi.org/10.1038/nature12291, 2013.

Keller, V. D. J., Tanguy, M., Prosdocimi, I., Terry, J. A., Hitt, O., Cole, S. J., Fry, M., Morris, D. G., and Dixon, H.: CEH-GEAR: $1 \mathrm{~km}$ resolution daily and monthly areal rainfall estimates for the UK for hydrological and other applications, Earth Syst. Sci. Data, 7, 143-155, https://doi.org/10.5194/essd-7-143-2015, 2015.

Koster, R. D. and Suarez, M. J.: Soil Moisture Memory in Climate Models, J. Hydrometeorol., 2, 558-570, https://doi.org/10.1175/15257541(2001)002<0558:SMMICM>2.0.CO;2, 2001.

Kotlarski, S., Keuler, K., Christensen, O. B., Colette, A., Déqué, M., Gobiet, A., Goergen, K., Jacob, D., Lüthi, D., van Meijgaard, E., Nikulin, G., Schär, C., Teichmann, C., Vautard, R., Warrach-Sagi, K., and Wulfmeyer, V.: Regional climate modeling on European scales: a joint standard evaluation of the EUROCORDEX RCM ensemble, Geosci. Model Dev., 7, 1297-1333, https://doi.org/10.5194/gmd-7-1297-2014, 2014.

Kruijt, B., Witte, J.-P. M., Jacobs, C. M., and Kroon, T.: Effects of rising atmospheric $\mathrm{CO}_{2}$ on evapotranspiration and soil moisture:
A practical approach for the Netherlands, J. Hydrol., 349, 257267, https://doi.org/10.1016/j.jhydrol.2007.10.052, 2008.

Kuhn, H. W.: The Hungarian method for the assignment problem, Nav. Res. Log., 2, 83-97, https://doi.org/10.1002/nav.3800020109, 1955.

Kuhn, H. W.: Variants of the hungarian method for assignment problems, Nav. Res. Log., 3, 253-258, https://doi.org/10.1002/nav.3800030404, 1956.

Lafon, T., Dadson, S., Buys, G., and Prudhomme, C.: Bias correction of daily precipitation simulated by a regional climate model: a comparison of methods, International J. Climatol., 33, 13671381, https://doi.org/10.1002/joc.3518, 2013.

Lawrence, B. N., Bennett, V. L., Churchill, J., Juckes, M., Kershaw, P., Pascoe, S., Pepler, S., Pritchard, M., and Stephens, A.: Storing and manipulating environmental big data with JASMIN, in: Big Data, 2013 IEEE International Conference on, pp. 68-75, https://doi.org/10.1109/BigData.2013.6691556, 2013.

Lorenz, E. N.: A study of the predictability of a 28variable atmospheric model, Tellus, 17, 321-333, https://doi.org/10.1111/j.2153-3490.1965.tb01424.x, 1965.

Massey, N., Jones, R., Otto, F. E. L., Aina, T., Wilson, S., Murphy, J. M., Hassell, D., Yamazaki, Y. H., and Allen, M. R.: weather@home - development and validation of a very large ensemble modelling system for probabilistic event attribution, Q. J. Roy. Meteor. Soc., 141, 1528-1545, https://doi.org/10.1002/qj.2455, 2015.

Meinshausen, M., Smith, S. J., Calvin, K., Daniel, J. S., Kainuma, M. L. T., Lamarque, J. F., Matsumoto, K., Montzka, S. A., Raper, S. C. B., Riahi, K., Thomson, A., Velders, G. J. M., and van Vuuren, D. P. P.: The RCP greenhouse gas concentrations and their extensions from 1765 to 2300, Climatic Change, 109, 213-241, https://doi.org/10.1007/s10584-011-0156-z, 2011.

Milly, P. and Dunne, K. A.: A Hydrologic Drying Bias in Water-Resource Impact Analyses of Anthropogenic Climate Change, J. Am. Water Resour. As., 53, 822-838, https://doi.org/10.1111/1752-1688.12538, 2017.

Milly, P. C. D. and Dunne, K. A.: Potential evapotranspiration and continental drying, Nat. Clim. Change, 6, 946-949, https://doi.org/10.1038/nclimate3046, 2016.

Miralles, D. G., Teuling, A. J., van Heerwaarden, C. C., and VilaGuerau de Arellano, J.: Mega-heatwave temperatures due to combined soil desiccation and atmospheric heat accumulation, Nat. Geosci., 7, 345-349, https://doi.org/10.1038/ngeo2141, 2014.

Monteith, J. L.: Evaporation and environment, in: Symp. Soc. Exp. Biol., vol. 19, p. 4, 1965.

Murphy, J. M., Sexton, D. M. H., Jenkins, G. J., Booth, B. B. B., Brown, C. C., Clark, R. T., Collins, M., Harris, G. R., Kendon, E. J., Betts, R. A., Brown, S. J., Humphrey, K. A., McCarthy, M. P., McDonald, R. E., Stephens, A., Wallace, C., Warren, R., Wilby, R., and Wood, R. A.: UK climate projections science report: climate change projections, Tech. rep., Met Office Hadley Centre, Exeter, 2009.

Nelsen, R. B.: An introduction to copulas, Springer Science \& Business Media, Springer-Verlag New York, https://doi.org/10.1007/0-387-28678-0, 2007.

Papadimitriou, C. H. and Steiglitz, K.: Combinatorial Optimization: Algorithms and Complexity, Prentice-Hall, Inc., Upper Saddle River, NJ, USA, 1982. 
R Core Team: R: A Language and Environment for Statistical Computing, R Foundation for Statistical Computing, Vienna, Austria, available at: https://www.R-project.org (last access: 25 October 2017), 2016.

Rayner, N. A., Parker, D. E., Horton, E. B., Folland, C. K., Alexander, L. V., Rowell, D. P., Kent, E. C., and Kaplan, A.: Global analyses of sea surface temperature, sea ice, and night marine air temperature since the late nineteenth century, J. Geophys. Res., 108, 4407, https://doi.org/10.1029/2002JD002670, 2003.

Robinson, E. L., Blyth, E., Clark, D. B., Finch, J., and Rudd, A. C.: Climate hydrology and ecology research support system potential evapotranspiration dataset for Great Britain (1961-2012) [CHESS-PE], https://doi.org/10.5285/d329f4d695ba-4134-b77a-a377e0755653, 2015.

Rodwell, M. J. and Folland, C. K.: Atlantic air-sea interaction and seasonal predictability, Q. J. Roy. Meteor. Soc., 128, 1413-1443, https://doi.org/10.1002/qj.200212858302, 2002.

Rodwell, M. J., Rowell, D. P., and Folland, C. K.: Oceanic forcing of the wintertime North Atlantic Oscillation and European climate, Nature, 398, 320-323, 1999.

Roundy, J. K., Ferguson, C. R., and Wood, E. F.: Temporal Variability of Land-Atmosphere Coupling and Its Implications for Drought over the Southeast United States, J. Hydrometeorol., 14, 622-635, https://doi.org/10.1175/JHM-D-12-090.1, 2013.

Rudd, A. C. and Kay, A. L.: Use of very high resolution climate model data for hydrological modelling: estimation of potential evaporation, Hydrol. Res., 47, 660-670, https://doi.org/10.2166/nh.2015.028, 2016.

Schaller, N., Kay, A. L., Lamb, R., Massey, N. R., van Oldenborgh, G. J., Otto, F. E. L., Sparrow, S. N., Vautard, R., Yiou, P., Ashpole, I., Bowery, A., Crooks, S. M., Haustein, K., Huntingford, C., Ingram, W. J., Jones, R. G., Legg, T., Miller, J., Skeggs, J., Wallom, D., Weisheimer, A., Wilson, S., Stott, P. A., and Allen, M. R.: Human influence on climate in the 2014 southern England winter floods and their impacts, Nat. Clim. Change, 6, 627-634, https://doi.org/10.1038/nclimate2927, 2016.

Seneviratne, S. I., Corti, T., Davin, E. L., Hirschi, M., Jaeger, E. B., Lehner, I., Orlowsky, B., and Teuling, A. J.: Investigating soil moisture-climate interactions in a changing climate: A review, Earth-Sci. Rev., 99, 125-161, https://doi.org/10.1016/j.earscirev.2010.02.004, 2010.
Seneviratne, S. I., Nicholls, N., Easterling, D., Goodess, C. M., Kanae, S., Kossin, J., Luo, Y., Marengo, J., McInnes, K., Rahimi, M., Reichstein, M., Sorteberg, A., Vera, C., and Zhang, X.: Managing the Risks of Extreme Events and Disasters to Advance Climate Change Adaptation, pp. 109-230, Cambridge University Press, Cambridge, UK, and New York, NY, USA, available at: http://ipcc-wg2.gov/SREX/, a Special Report of Working Groups I and II of the Intergovernmental Panel on Climate Change (IPPC), 2012.

Sheffield, J., Wood, E. F., and Roderick, M. L.: Little change in global drought over the past 60 years, Nature, 491, 435-438, https://doi.org/10.1038/nature11575, 2012.

Shu, Q., Song, Z., and Qiao, F.: Assessment of sea ice simulations in the CMIP5 models, The Cryosphere, 9, 399-409, https://doi.org/10.5194/tc-9-399-2015, 2015.

Tanguy, M., Dixon, H., Prosdocimi, I., and Morris, D. G.and Keller, V. D. J.: Gridded estimates of daily and monthly areal rainfall for the United Kingdom (1890-2014) [CEHGEAR], https://doi.org/10.5285/f2856ee8-da6e-4b67-bedb$590520 \mathrm{c} 77 \mathrm{~b} 3 \mathrm{c}, 2015$.

Taylor, K. E., Stouffer, R. J., and Meehl, G. A.: An Overview of CMIP5 and the Experiment Design, B. Am. Meteorol. Soc., 93, 485-498, https://doi.org/10.1175/BAMS-D-11-00094.1, 2012.

Teutschbein, C. and Seibert, J.: Bias correction of regional climate model simulations for hydrological climate-change impact studies: Review and evaluation of different methods, J. Hydrol., 456457, 12-29, https://doi.org/10.1016/j.jhydrol.2012.05.052, 2012.

Titchner, H. A. and Rayner, N. A.: The Met Office Hadley Centre sea ice and sea surface temperature data set, version 2: 1. Sea ice concentrations, J. Geophys. Res., 119, 2864-2889, https://doi.org/10.1002/2013JD020316, 2014.

Wilks, D.: Statistical Methods in the Atmospheric Sciences, Academic Press, Academic Press, available at: https://books.google. co.uk/books?id=IJuCVtQ0ySIC (last access: 25 October 2017), 2011.

Woollings, T., Franzke, C., Hodson, D. L. R., Dong, B., Barnes, E. A., Raible, C. C., and Pinto, J. G.: Contrasting interannual and multidecadal NAO variability, Clim. Dynam., 45, 539-556, https://doi.org/10.1007/s00382-014-2237-y, 2015. 